\title{
DFOS Applications to Geo-Engineering Monitoring
}

\author{
Bin SHI*, Dan ZHANG, Honghu ZHU, Chengcheng ZHANG, Kai GU, \\ Hongwei SANG, Heming HAN, Mengya SUN, and Jie LIU
}

\author{
School of Earth Sciences and Engineering, Nanjing University, Nanjing 210023, China \\ *Corresponding author: Bin SHI E-mail: shibin@nju.edu.cn
}

\begin{abstract}
Optical fiber sensing technology has developed rapidly since the 1980s with the development of the optical fiber and fiber optical communication technology. It is a new type of sensing technology that uses light as a carrier and optical fiber as a medium to sense and transmit external signals (measurands). Distributed fiber optical sensors (DFOS) can continuously measure the external physical parameters distributed along the geometric path of the optical fiber. Meanwhile, the spatial distribution and change information of the measured physical parameters over time can be obtained. This technology has unmatched advantages over traditional point-wise and electrical measurement monitoring technologies. This paper summarizes the state-of-the-art research of the application of the distributed optical fiber sensing technology in geo-engineering in the past 10 years, mainly including the advantages of DFOS, the challenges in geo-engineering monitoring, related fundamental theoretical issues, sensing performance of the optical sensing cables, distributed optical fiber monitoring system for geo-engineering, and applications of optical fiber sensing technology in geo-engineering.
\end{abstract}

Keywords: Distributed fiber optical sensors (DFOS); geo-engineering; sensing cables; applications, monitoring

Citation: Bin SHI, Dan ZHANG, Honghu ZHU, Chengcheng ZHANG, Kai GU, Hongwei SANG, et al., "DFOS Applications to Geo-Engineering Monitoring," Photonic Sensors, 2021, 11(2): 158-186.

\section{Introduction}

China is one of the countries with the most severe geohazards and the most threatened population in the world. Due to complex geological conditions and frequent tectonic activities, hazards such as rockfall, landslides, debris flows, the ground collapses, ground subsidence, and ground fissures are widely distributed and highly concealed, sudden and destructive, and are difficult to prevent. In recent years, affected by extreme weather, earthquakes, and engineering constructions, geohazards occurred frequently, causing serious losses to people's lives and properties. According to the Ministry of Natural Resources of China, the direct economic loss from geohazards in 2019 alone reached 2.77 billion yuan. On the other hand, in large-scale foundation engineering constructions, various geotechnical engineering problems emerged, such as foundation pit failure, tunnel deformation, and leakage, diaphragm wall collapse, and differential settlement. These have brought many hidden dangers to engineering safety, greatly increased the construction and operation costs, prolonged the project cycle, and caused a lot of life and property losses. Therefore, preventing and controlling geohazards and solving all kinds of geotechnical engineering problems is the central task for geo-engineering researchers and

Received: 25 December 2020 / Revised: 24 February 2021

(C) The Author(s) 2021. This article is published with open access at Springerlink.com DOI: $10.1007 / \mathrm{s} 13320-021-0620-\mathrm{y}$

Article type: Review 
practitioners and a major national demand, and monitoring is a prerequisite for this work.

Geohazards and geotechnical engineering are featured with large scale, multi-field effects, complex influencing factors, strong concealment, spanning multiple regions, harsh environments, high real-time monitoring requirements, and long monitoring periods. Because of these characteristics, the current point-wise electrical sensing technologies are still difficult to meet the needs of hazard prevention and mitigation, and have brought huge challenges to hazard warning, forecasting, and prevention.

The fiber optic sensing technology, which has developed rapidly with the development of optical fiber and fiber optic communication technology since 1980s, has the advantages of distributed and long-distance measurement, anti-interference, and corrosion resistance. Therefore, it has been increasingly used in geohazard and geotechnical engineering monitoring [1]. In the early days, the quasi-distributed fiber Bragg grating (FBG) technology and the fully distributed optical time-domain reflectometry (OTDR) technology were mainly used. In the past ten years, with the development of fully distributed fiber optic sensing technologies such as Raman optical time-domain reflectometry (ROTDR), Brillouin optical time-domain reflectometry (BOTDR), Brillouin optical time-domain analysis (BOTDA), and Brillouin optical frequency-domain analysis (BOFDA), the fully distributed monitoring technology for geo-engineering has also developed rapidly. Iten and Puzrin [2] buried fiber optic cables in an asphalt road passing through a creeping landslide and localized the landslide boundary by monitoring the deformation of the asphalt with BOTDA. Habel et al. [3] developed a GeoStab sensor based on the FBG technology and accurately detected the position of the sliding surface of a slope in an open coal pit. Soga's group [4-9] applied the BOTDR technology to foundation pile testing and tunnel deformation monitoring. Researchers [10-12] from the University of Campania "Luigi Vanvitelli" (formerly the Second University of Naples) in Italy applied BOTDA to laboratory landslide model tests, revealing the failure mechanism of pyroclastic soil slopes under rainfall infiltration. Based on the FBG sensing technology, Huang's group [13-15] has successively developed various types of fiber optic sensors suitable for slope monitoring, such as pressuremeters, pore pressure gauges, displacement gauges, and axial force gauges, which have been successfully applied to field landslide monitoring. Yin's group [16-19] developed FBG-based sensing rods, inclinometers, displacement meters, etc., and successfully applied them to GFRP soil nail pullout tests, dam model tests, debris flow, and slope monitoring. In Chinese mainland, with the rapid development of infrastructure construction and the urgent need for monitoring technology, a large number of research and application results related to geo-engineering fiber optic monitoring emerged. The authors' group [20] has carried out a lot of research on distributed monitoring technology of strain, temperature, and deformation in geo-engineering, and achieved many important results. In the past five years, research on the distributed sensing of water content and seepage of rock and soil mass has also made breakthroughs [21-23]. Liu et al. [24] used the BOTDR technology to conduct long-term monitoring of anti-slide piles of a highway slope. Chai et al. [25] applied the BOTDA to three-dimensional model tests of coal mining.

Combined with the research results of the authors' group, this review makes a general summary of research on fiber optic monitoring in geo-engineering in the past ten years.

\section{Characteristics of geological body and monitoring requirements}

Different from man-made structures such as reinforced concrete structures, steel structures, and 
synthetic material structures, geological bodies are the products of natural history and are a multiphase system consisting of solid, gas, and liquid. The rock mass is hard and its structure is complex. On the other side, the soft soil not only has the characteristics of porousness and low strength but also is constantly affected by natural and human engineering activities. From the perspective of geo-engineering monitoring, geological bodies have the following characteristics and put forward higher requirements for the monitoring technology.

(1) Complex structure and large spatial variability

After a long process of geological evolution, geological bodies have a very complex structure, large spatial variability, and high uncertainty. Therefore, the monitoring technology should have the function of distributed monitoring to prevent missing key factors of geological bodies.

(2) Large scale, long distance, and great depth

The scale, scope, and depth of geological bodies related to various projects are much larger than the structures. Such as large-scale slopes with a volume of tens of millions of cubic meters, river embankments with a length of tens or even hundreds of kilometers, and mines with an influence depth reaching thousands of meters. Therefore, to understand the dynamic process of such a large geological body, a long-distance and well-covered monitoring system is necessary to obtain sufficient information on various parameters of the geological body.

(3) Weak penetration and strong concealment

It is hard to go to the sky and even harder to enter the ground. The geological body is composed of the rock mass, soil, and fluid, which is not easy to penetrate for the detection signal. Meanwhile, underground lithology and environmental factors are complex and difficult to grasp intuitively. This poses a huge challenge for the installation of monitoring components.
(4) Multi-field effects and complicated influencing factors

Since the surface of the crust is at the junction of the lithosphere, hydrosphere, atmosphere, and biosphere, it is bound to be coupled by multiple fields such as stress, temperature, moisture, water flow, and chemicals. This leads to the demand for multi-fields and multi-parameters monitoring function for the monitoring technology.

(5) Irregular shape and diverse geological environment

The shapes of natural geological bodies and engineering rock-soil bodies are generally irregular, forming a variety of landforms. The irregularity of the shape causes difficulties to the installation of monitoring components, data processing, and mechanism analysis. The geological environment is complex and changeable, such as high mountains and deep valleys, high and low temperatures, and shallow and deep subsurface parts. This brings great challenges to the installation and protection of the geological monitoring system, as well as the reliability and durability of the system.

\section{Shortcoming of conventional monitoring technologies}

It is not easy to obtain multi-field and multi-parameter of geological bodies and the geotechnical engineering structures accurately, timely, and on a large scale. It requires an advanced monitoring system and advanced theories and methods.

At present, conventional monitoring technologies for geological and geotechnical engineering mainly use vibrating wire sensors and resistive sensors in point monitoring mode. Figure 1 summarizes the commonly used contact-type monitoring technologies for rock and soil deformation. The limited monitoring points of these technologies may lead to the problems of missed detection and blind spots. They are not suitable for the large-scale, long-distance, and great-depth 
monitoring in rocks and soils. Meanwhile, sensors are often subjected to harsh environments such as high temperature, low temperature, high pressure, and high humidity, which are great threats to the sensors and lead to low survival rates, corrosion, and poor durability. Sensors based on the principle of electromagnetic induction are susceptible to electromagnetic interference. They may have a long-term zero drift, which causes poor monitoring accuracy and stability. Generally, the deficiencies of these monitoring technologies obstruct a better understanding of the dynamic process of geological disasters and geotechnical engineering problems and therefore weaken the ability of long-term monitoring, prediction, and early warning. It is necessary to develop advanced geological and geotechnical engineering monitoring technologies to provide strong support to the theoretical research and engineering applications in geological disasters and geotechnical engineering.

\section{Advantages of DFOS and its challenges to geo-engineering monitoring}

In the optical fiber sensing technology, the distributed fiber optical sensors (DFOS) is very suitable for geo-engineering long-distance, long-period, and distributed monitoring because of its advantages such as distributed measurement capability, anti-electromagnetic interference, corrosion resistance, flexiblity, and ease to implement network monitoring. In DFOS techniques, the sensing fiber is structured into a one-dimensional, two-dimensional, or three-dimensional network according to a certain topology. It is like a sensory neural network, which is planted in a "dead" geological body, forming a geo-aware system (Fig. 1) and monitoring the relevant changes of measurement object in longitude, plane, and three dimensions. This technique overcomes the disadvantages of the traditional point monitoring method and improves the success ratio and effectiveness. Therefore, DFOS is particularly useful for overall strain and temperature monitoring in large geo-engineering such as uneven land subsidence in long-distance tunnel, ground crack distribution and deformation on a large scale, oil and gas pipeline leakage, dam and embankment leakage, and slope stability. The characteristics and deficiencies of distributed fiber optic sensing techniques in geo-engineering are listed in Table 1.

As shown in Table 1, the DFOS technology is a collection of various sensing techniques with different measurement variations and principles, and each technique has its characteristics and shortcomings. Therefore, suitable technology with a specific monitoring scheme should be selected, according to different monitoring objects and requirements.

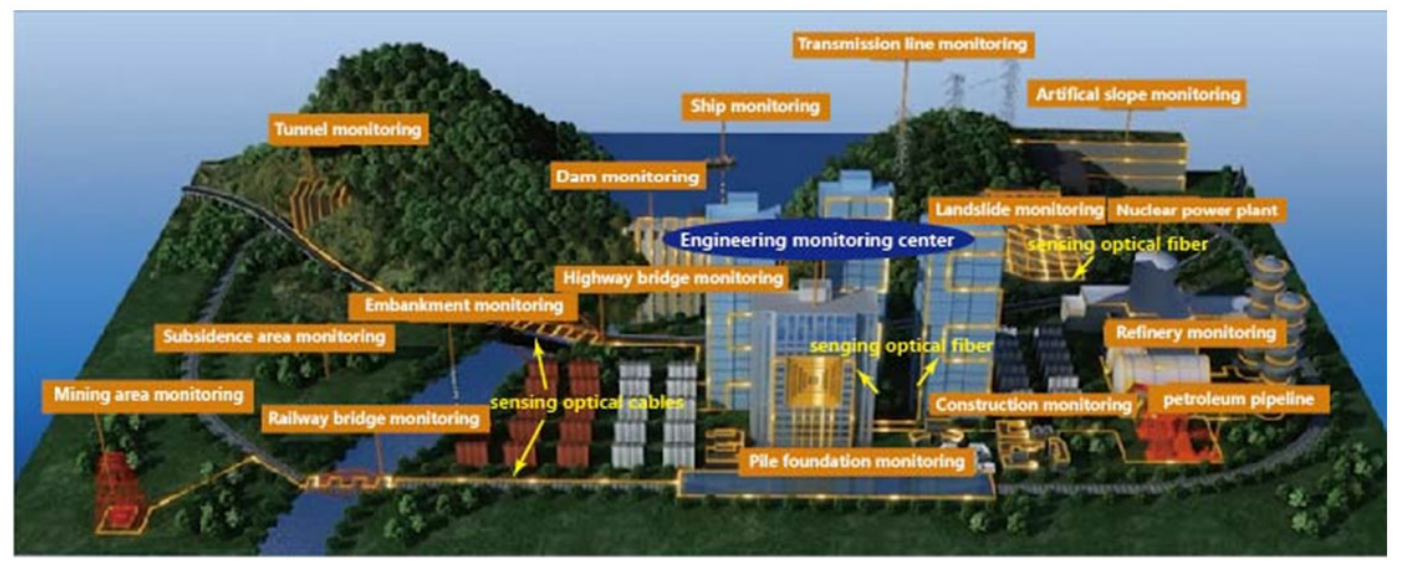

Fig. 1 Distributed fiber geo-aware system concept diagram (the yellow highlight line in the figure is sensing fiber). 
However, as mentioned in Section 1, because random behavior of rock and soil in multiple of the complex structure of the geological body, the multi-cracking properties of the rock mass, the multi-pore structure of soft soil, and the

fields, the application of DFOS in geo-engineering monitoring faces many challenges.

Table 1 Characteristics and deficiencies of distributed fiber optic sensing techniques in geo-engineering.

\begin{tabular}{|c|c|c|c|c|c|c|}
\hline Methods & Techniques & Principle & $\begin{array}{c}\text { Direct } \\
\text { variation }\end{array}$ & $\begin{array}{c}\text { Extended variation or } \\
\text { event }\end{array}$ & Characteristics & Shortcomings \\
\hline $\begin{array}{l}\text { Quasi- } \\
\text { distributed }\end{array}$ & FBG & $\begin{array}{l}\text { Constructive } \\
\text { interference }\end{array}$ & Wavelength & \begin{tabular}{|c|} 
Temperature, strain, \\
pressure, displacement, \\
torque, acceleration, \\
current, voltage, magnetic \\
field, frequency, vibration, \\
moisture, seepage, water \\
level, and pore water \\
pressure
\end{tabular} & $\begin{array}{l}\text { Simple structure, small size, } \\
\text { lightweight, good compatibility, low } \\
\text { optical loss, high reliability, } \\
\text { corrosion resistance, } \\
\text { anti-electromagnetic interference, } \\
\text { and high sensitivity }\end{array}$ & $\begin{array}{l}\text { The grating will subside under } \\
\text { high temperature, and easy to } \\
\text { chirp under sticking and } \\
\text { compression. It is easy to be } \\
\text { damaged when processed, and } \\
\text { some information will be blocked } \\
\text { because of quasi-distribution }\end{array}$ \\
\hline \multirow{6}{*}{$\begin{array}{c}\text { Fully } \\
\text { distributed }\end{array}$} & $\begin{array}{l}\text { Optical time } \\
\text { domain reflector } \\
\text { (OTDR) }\end{array}$ & $\begin{array}{l}\text { Rayleigh } \\
\text { scattering }\end{array}$ & Optical loss & $\begin{array}{l}\text { Cracking, bending, } \\
\text { breakpoint, displacement, } \\
\text { pressure }\end{array}$ & $\begin{array}{l}\text { Single-end measurement, portable, } \\
\text { intuitive, fast, accurate measurement } \\
\text { of optical fiber light loss and } \\
\text { breakpoint bending position, } \\
\text { measurement of the structure } \\
\text { cracking, and breaking position }\end{array}$ & $\begin{array}{l}\text { Many factors that influence } \\
\text { monitoring and low accuracy }\end{array}$ \\
\hline & $\begin{array}{l}\text { Raman optical } \\
\text { time domain } \\
\text { reflector } \\
\text { (ROTDR) }\end{array}$ & $\begin{array}{l}\text { Raman } \\
\text { scattering }\end{array}$ & $\begin{array}{l}\text { (Anti) Stokes } \\
\text { Raman } \\
\text { intensity ratio }\end{array}$ & $\begin{array}{c}\text { Temperature, moisture } \\
\text { content, seepage, water } \\
\text { level, etc. }\end{array}$ & $\begin{array}{l}\text { Single-end measurement, } \\
\text { temperature-sensitive only, and } \\
\text { long-distance measurement }\end{array}$ & $\begin{array}{l}\text { Low spatial resolution and } \\
\text { accuracy }\end{array}$ \\
\hline & $\begin{array}{l}\text { Brillouin optical } \\
\text { time domain } \\
\text { reflector } \\
\text { (BOTDR) }\end{array}$ & $\begin{array}{l}\text { Brillouin } \\
\text { scattering }\end{array}$ & $\begin{array}{l}\text { Spontaneous } \\
\text { Brillouin } \\
\text { scattering } \\
\text { optical power } \\
\text { or frequency } \\
\text { shift }\end{array}$ & $\begin{array}{c}\text { Strain, temperature, } \\
\text { displacement, deformation, } \\
\text { and deflection }\end{array}$ & $\begin{array}{c}\text { Single-end measurement, } \\
\text { measurement of the absolute value } \\
\text { of temperature and strain, and } \\
\text { breakpoints }\end{array}$ & $\begin{array}{l}\text { Long measuring time and low } \\
\text { spatial resolution }\end{array}$ \\
\hline & $\begin{array}{l}\text { Brillouin optical } \\
\text { time domain } \\
\text { analysis } \\
\text { (BOTDA) }\end{array}$ & $\begin{array}{l}\text { Brillouin } \\
\text { scattering }\end{array}$ & \begin{tabular}{c|} 
Stimulated \\
Brillouin \\
scattering \\
optical power \\
or frequency \\
shift
\end{tabular} & $\begin{array}{c}\text { Strain, temperature, } \\
\text { displacement, deformation, } \\
\text { and deflection }\end{array}$ & $\begin{array}{c}\text { Double-end measurement, large } \\
\text { measuring range, short testing time, } \\
\text { high accuracy, high spatial } \\
\text { resolution, measurement of the } \\
\text { absolute value of temperature, and } \\
\text { strain }\end{array}$ & $\begin{array}{l}\text { Unable to detect breakpoints, } \\
\text { high monitoring risk brought by } \\
\text { double-end measurement }\end{array}$ \\
\hline & $\begin{array}{c}\text { Brillouin optical } \\
\text { frequency domain } \\
\text { analysis } \\
\text { (BOFDA) }\end{array}$ & $\begin{array}{l}\text { Brillouin } \\
\text { scattering }\end{array}$ & \begin{tabular}{c|} 
Stimulated \\
Brillouin \\
scattering \\
optical power \\
or frequency \\
shift
\end{tabular} & $\begin{array}{c}\text { Strain, temperature, } \\
\text { displacement, deformation, } \\
\text { and deflection }\end{array}$ & $\begin{array}{c}\text { High signal-to-noise ratio, large } \\
\text { measurement range, high precision, } \\
\text { high spatial resolution, and } \\
\text { measurement of the absolute value } \\
\text { of temperature and strain }\end{array}$ & $\begin{array}{l}\text { High coherence of light source, } \\
\text { short-distance monitoring, unable } \\
\text { to detect breakpoints, and high } \\
\text { monitoring risk brought by } \\
\text { double-end measurement }\end{array}$ \\
\hline & $\begin{array}{l}\text { Phase-sensitive } \\
\text { optical time } \\
\text { domain reflector } \\
(\varphi \text {-OTDR })\end{array}$ & $\begin{array}{l}\text { Rayleigh } \\
\text { scattering }\end{array}$ & $\begin{array}{c}\text { Phase variation } \\
\text { of Rayleigh } \\
\text { scattering light }\end{array}$ & $\begin{array}{l}\text { Vibration, sound waves, } \\
\text { seismic waves, and } \\
\text { abnormal events that } \\
\text { produce vibration signals }\end{array}$ & $\begin{array}{l}\text { Single-end measurement, high } \\
\text { sensitivity, large monitoring area, } \\
\text { and paved communication fiber } \\
\text { optic cables used }\end{array}$ & $\begin{array}{c}\text { Low signal-to-noise ratio } \\
\text { compared with the traditional } \\
\text { detector, one component } \\
\text { measurement, and a large amount } \\
\text { of data }\end{array}$ \\
\hline
\end{tabular}

(1) Theoretical challenges. To apply the fiber optic sensing technology to geo-engineering monitoring, three basic theoretical problems must be solved. (a) Standards for evaluating the performance of the bare fiber encapsulated in optical cables should be established to provide a theoretical basis for the development and correction of sensing cables. (b) Sensing optical cables must be coupled with rock and soil to be tested for accurate measurement, hence a criterion for evaluating the coupling is required. (c) It is necessary to establish the corresponding characterization model between the basic quantities measured by DFOS and other measured parameters to realize the multi-parameters monitoring of geological engineering with DFOS.

(2) Technical challenges. According to the requirements of geo-engineering monitoring, three technical bottlenecks of sensing cables must be 
solved. (a) How to develop a sensing fiber optic cable that is both robust and sensitive? (b) The measuring scope of ordinary optical fibers generally does not exceed $2 \%$, and how to develop sensing cables to meet the monitoring requirements of large deformation? (c) To estimate the moisture, seepage, and micro-seismic monitoring of geological bodies, special sensitivity enhanced fiber should be developed.

(3) Application challenges. Besides theoretical and technical challenges, the application of fiber optic sensing techniques to geo-engineering monitoring requires the corresponding DFOS monitoring system and construction method to install and maintain optical cables for different monitoring quantities.

In recent years, many researchers have carried out fruitful research and achieved a series of the breakthrough. Thus, geo-engineering DFOS monitoring techniques are greatly promoted, and the application field is extended.

\section{Geo-monitoring theoretical issues of FOS}

\subsection{Strain transfer analysis}

Bare fibers less than $0.25 \mathrm{~mm}$ in diameter are too fragile to be used directly as sensing elements for geoengineering monitoring; they should be well coated and jacketed to survive in the harsh geologic environment (Fig. 2) [26]. However, the sensitivity of these cables will inevitably be affected by the multi-buffers. Strain transfer analysis is therefore important to retrieve the actual strain present in the monitored soil or rock. Most existing strain transfer models have assumed that the strain of host material is evenly distributed [27, 28]. We performed elaborate matrix-to-fiber strain transfer analysis considering uneven matrix strain distributions and matrix-fiber interface decoupling (Fig. 3) [29], which is summarized here. In the following descriptions, $r$ and $D$ represent the radius and diameter, respectively; $\tau$ and $\varepsilon$ represent the shear stress and normal strain, respectively; $G$ and $E$ represent the shear modulus and Young's modulus, respectively; the subscripts $m, p$, and $g$, denote the matrix, protective layer, and fiber core, respectively.

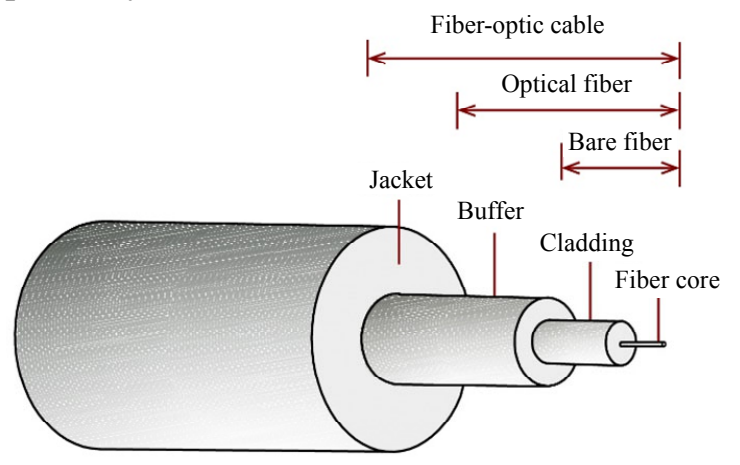

Fig. 2 Typical structure of a fiber-optic cable.

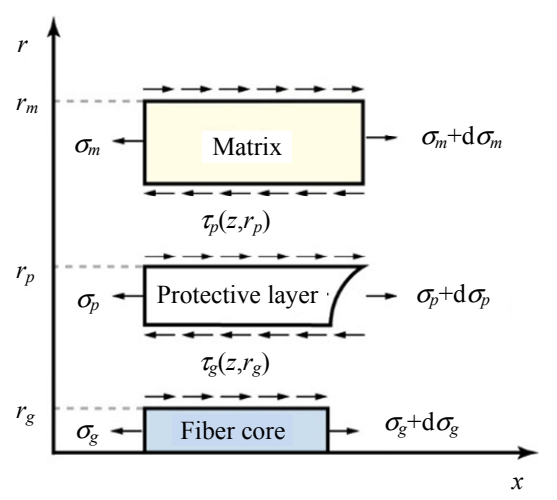

Fig. 3 Strain transfer analysis.

We first considered a parabolic matrix strain distribution (Fig. 4):

$$
\varepsilon_{m}(x)=-\frac{\varepsilon_{0}}{L^{2}} x^{2}+\varepsilon_{0}
$$

where $\varepsilon_{m}$ is the matrix strain; $L$ is the half of the fiber embedment length; $\varepsilon_{0}$ is the maximum strain at the midpoint; $x$ is the horizontal axis. Based on the shear-lag theory, we derived the strain transfer ratio as

$$
\begin{aligned}
& \alpha(x)=\frac{\varepsilon_{g}(x)}{\varepsilon_{m}(x)} \\
& =\frac{2 k r_{p}}{E_{g} n^{2} r_{g}^{2}}\left[\frac{2 L}{n} \frac{\cosh (n x)-\cosh (n L)}{\sinh (n L)\left(L^{2}-x^{2}\right)}+1\right]
\end{aligned}
$$




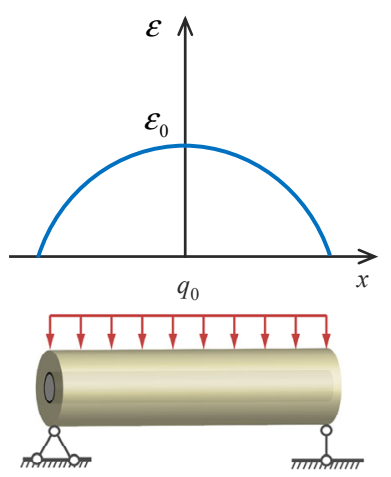

Fig. 4 Parabolic matrix strain distribution.

where $k$ and $n$ have the following forms, respectively:

$$
\begin{gathered}
n=\sqrt{\frac{2 G_{p}}{r_{g}^{2} E_{g} \ln \frac{r_{p}}{r_{g}}}} \\
k=\frac{G_{p}}{r_{p} \ln \frac{r_{p}}{r_{g}}} .
\end{gathered}
$$

We then investigated the situation where the matrix-fiber interface decoupling occurs during the monitoring process. Figure 5 shows the assumed distribution of interface shear stress $\tau_{\mathrm{mp}}$ which can be divided into three zones. In the first zone adjacent to the fiber head $\left(0 \leq l \leq L_{\text {move }}\right)$, the matrix and fiber decouple and $\tau_{\mathrm{mp}}$ equals to the residual interface shear strength $\tau_{\text {res }}$. In the second zone $\left(L_{\text {move }}<l \leq L_{s}\right)$, $\tau_{\mathrm{mp}}$ is linearly distributed, decreasing from the peak interface shear strength $\tau_{\max }$ to zero. In the third zone $\left(l>L_{s}\right), \quad \tau_{\mathrm{mp}}$ is not mobilized and the monitored strain is equivalent to the matrix strain.

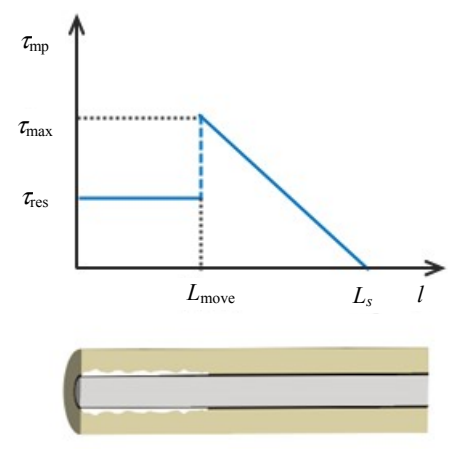

Fig. 5 Matrix-fiber interface decoupling.

The interface shear stress $\tau_{\mathrm{mp}}$ in the first and second zones can be expressed by

$$
\tau_{\mathrm{mp}}= \begin{cases}\tau_{\text {res }} & \left(0 \leqslant l \leqslant L_{\text {move }}\right) \\ \frac{\tau_{\max }}{L_{\text {move }}-L_{s}} l+\frac{\tau_{\max } L_{s}}{L_{s}-L_{\text {move }}} & \left(L_{\text {move }}<l \leqslant L_{s}\right)\end{cases}
$$

and $L_{\text {move }}$ and $L_{s}$ can respectively be derived as

$$
\begin{gathered}
L_{\text {move }}=\frac{r_{g}^{2} E_{g} \varepsilon_{m}}{2 r_{p}\left(\tau_{\text {max }}-\tau_{\text {res }}\right)} \\
L_{s}=\frac{-L_{\text {move }}+\sqrt{25 L_{\text {move }}^{2}-\frac{72 \varepsilon_{m}\left(L_{\text {move }}-L\right)}{B \tau_{\text {max }}}}}{6}
\end{gathered}
$$

where

$$
B=\frac{1}{E_{p}}\left(\frac{1}{r_{f}}-\frac{1}{r_{p}}\right) .
$$

If $\tau_{\max }$ and $\tau_{\text {res }}$ are determined, the lengths of the first and second zones can be calculated.

\subsection{Cable-soil coupling evaluation}

When the sensing cables are installed in the ground for monitoring, the coupling between the cable and the soil directly affects the accuracy of fiber-optic measurements, among which the deformation coupling is the most critical [1, 30-36].

\subsubsection{Shear strength criterion for interface bond}

A shear strength-based criterion was proposed for determining the bond state of a cable-soil interface [32, 37] and was further developed by Zhang et al. [38]. Laboratory evidence showed that the cable-soil interface failed progressively, exhibiting strain-softening, or strain-hardening behavior depending on the soil properties [32, 33]. Hence, by comparing the interface shear stress with the peak or residual shear strength $\left(\tau_{\max }\right.$ or $\left.\tau_{\text {res }}\right)$, the bond state of the interface can be determined. $\tau_{\max }$ and $\tau_{\text {res }}$ may be estimated based on the Mohr-Coulomb failure criterion:

$$
\begin{gathered}
\tau_{\text {max }}=c_{\text {max }}+\sigma_{h} \tan \delta_{\text {max }} \\
\tau_{\text {res }}=c_{\text {res }}+\sigma_{h} \tan \delta_{\text {res }}
\end{gathered}
$$

where $c_{\max }$ and $\delta_{\max }$ are the peak cable-soil interface cohesion and friction angle, respectively; $c_{\text {res }}$ and $\delta_{\text {res }}$ are the residual cable-soil interface 
cohesion and friction angle, respectively; $\sigma_{h}$ is the confining pressure normal to the cable axis. On the other hand, the cable-soil interface shear stress $\tau_{c}$ may be determined by using

$$
\tau_{c}=\frac{E_{c} D_{c}}{4} \frac{\mathrm{d} \varepsilon}{\mathrm{d} z} \approx \frac{E_{c} D_{c}}{4} \frac{\Delta \varepsilon}{\Delta z}
$$

where $E_{c}$ and $D_{c}$ are Young's modulus and cross-sectional area of the cable, respectively; $\varepsilon$ is the monitored strain; $\mathrm{d} \varepsilon / \mathrm{d} z$ is the gradient of the monitored strain; $\Delta \varepsilon$ is the difference in strain between two adjacent measuring points; $\Delta z$ is the spatial sampling interval.

The critical confining pressure $\sigma_{h, \mathrm{cr}}$ and the bond depth $h_{\text {cr }}$ were proposed to further characterize the cable-soil interface bond [38], which are respectively given by

$$
\begin{gathered}
\sigma_{h, \mathrm{cr}}=\frac{E_{c} D_{c}}{4 \tan \delta_{\max }}\left[\frac{\mathrm{d} \varepsilon}{\mathrm{d} z}\right]_{\max }-\frac{c_{\max }}{\tan \delta_{\max }} \\
h_{\mathrm{cr}}=\frac{E_{\mathrm{c}} D_{\mathrm{c}}}{4 K \gamma \tan \delta_{\max }}\left[\frac{\mathrm{d} \varepsilon}{\mathrm{d} z}\right]_{\max }-\frac{c_{\max }}{K \gamma \tan \delta_{\max }}
\end{gathered}
$$

where $[\mathrm{d} \varepsilon / \mathrm{d} z]_{\max }$ is the maximum strain gradient, $K$ is the lateral earth pressure coefficient, and $\gamma$ is the bulk unit weight of the overlying ground. For a low value of $[\mathrm{d} \varepsilon / \mathrm{d} z]_{\max }$, a small $h_{\mathrm{cr}}$ is required to guarantee a good cable-soil interface bond which is desirable in engineering practice.

\subsubsection{Microanchor failure criterion}

The cable-soil interface is likely to fail under low confining pressures. To address this problem, researchers have proposed to install microanchors on the cable coating to increase the cable-soil interface shear strength [12, 39-42]. In this regard, the deformation coupling between a microanchored cable and surrounding soil can also be evaluated by using the shear strength criterion [43, 44]. Alternatively, the microanchored cable-soil deformation coupling may be assessed by using the geotechnical bearing capacity theory (Fig. 6) [45].

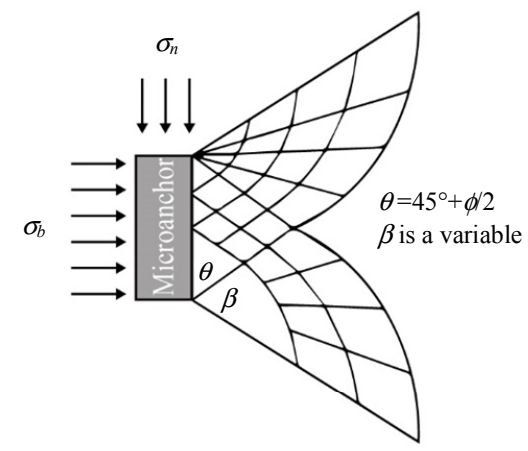

Fig. 6 Modified punching shear failure mechanism of the fiber-optic cable microanchor.

The force $F_{a}$ applied on a microanchor (interaction force between the microanchor and soil) can be derived based on the measured strain:

$$
F_{a}=\frac{\pi}{4} D_{c}^{2} E_{c} \Delta \varepsilon_{c}
$$

where $\Delta \varepsilon_{\mathrm{c}}$ is the difference in strain measured by the two adjacent unanchored cable segments.

For the three microanchor types shown in Fig. 6, the ultimate anchor-soil interaction force $F_{\mathrm{ar}}$ can be derived from the bearing capacity theory as

$$
F_{\mathrm{ar}}= \begin{cases}\frac{\pi}{4}\left(\sigma_{n} N_{q}+c N_{c}\right)\left(D_{a}^{2}-D_{c}^{2}\right) & \text { (Disc) } \\ \pi D_{a} L_{a}\left(c_{i}+\sigma_{n} \tan \phi_{i}\right)+\frac{\pi}{4}\left(\sigma_{n} N_{q}+c N_{c}\right)\left(D_{a}^{2}-D_{c}^{2}\right) & \text { (Cylinder) } \\ \pi D_{a}\left(L_{a}+2 H_{a}\right)\left(c_{i}+\sigma_{n} \tan \phi_{i}\right)+\frac{\pi}{4}\left(\sigma_{n} N_{q}+c N_{c}\right)\left(D_{a}^{2}-D_{c}^{2}\right) & \text { (Spindle) }\end{cases}
$$

where $\sigma_{n}$ is the applied stress normal to the cable axis; $c_{i}$ and $\phi_{i}$ are the cohesion and friction angle of the anchor-soil interface; $D_{a}, L_{a}$, and $H_{a}$ are the dimensions of the microanchors (see Fig. 7); $N_{q}$ and $N_{c}$ are the bearing capacity factors.

If the microanchor has not reached its capacity (i.e., $F_{a}<F_{\text {ar }}$ ), it is considered that the cable couples to the surrounding soil and the strain measurements are reliable. 


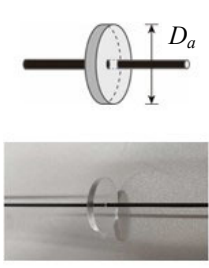

(a)

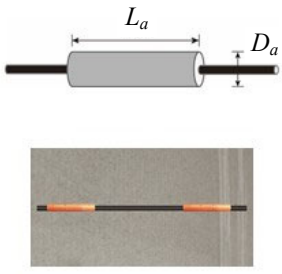

(b)

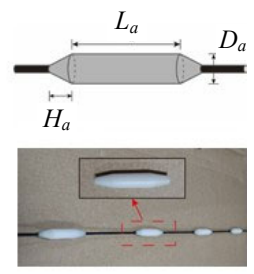

(c)
Fig. 7 Three typical fiber-optic cable microanchors: (a) disc, (b) cylinder, and (c) spindle.

\subsubsection{Cable-soil coupling index}

To make the cable-soil coupling evaluation operational, laboratory pullout tests can be conducted where a fiber-optic cable is gradually pulled out from a confined soil under increasing pullout displacements and the strain distributions along the cable are simultaneously measured. We devised such a displacement-controlled pullout apparatus as shown in Fig. 8 [46]. The apparatus consists of (1) a pressure chamber where a confining pressure can be applied to a specimen up to megapascals; (2) a tensile tester for applying pullout forces/ displacements to a fiber-optic cable embedded in the specimen; (3) a fiber-optic interrogator for recording strain distributions along the cable.

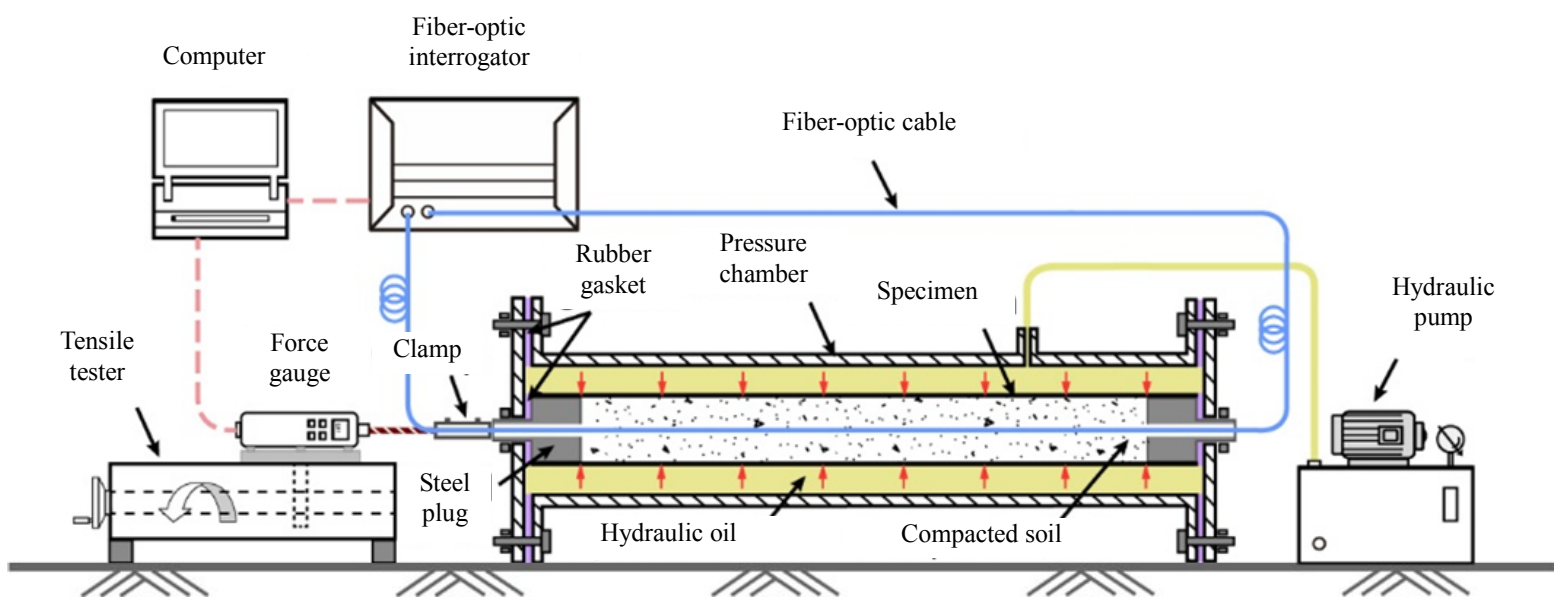

Fig. 8 Test apparatus for investigating the fiber-optic cable-soil interaction.

In a pullout test, a series of strain profiles can be obtained. For a given strain profile, the strain propagation length $d_{\varepsilon}$ can be determined as the farthest propagation length of strain from the cable head toward the toe. Further, the maximum strain propagation length for all the strain profiles under a certain confining pressure is denoted by $d_{\varepsilon}^{\max }$. Based on this concept, we proposed a cable-soil coupling index $\zeta_{c-s}$ to quantitatively evaluate the cable-soil coupling, which is given by

$$
\zeta_{c-s}=\left(1-\frac{d_{\varepsilon}^{\max }}{L_{0}}\right) \times 100 \%
$$

where $L_{0}$ is the length of the cable embedded in the specimen. According to this index, the cable-soil coupling condition can be classified; Table 2 shows such an example.
Table 2 Classification of cable-soil coupling condition based on the index $\zeta_{c-s}$.

\begin{tabular}{cc}
\hline$\zeta_{c-s}(\%)$ & Rate of coupling condition \\
\hline $75-100$ & Excellent \\
$50-75$ & Good \\
$25-50$ & Fair \\
$0-25$ & Poor \\
\hline
\end{tabular}

\subsection{Transformation representation models for multi-parameter sensing}

The basic physical quantities directly measured by DFOS are limited, mainly including temperature, strain, and vibration. To monitor other physical quantities (e.g., water content, seepage, density, and humanity) from measurements of the basic ones, a transformation representation model must be established between them to achieve multi-parameter geoengineering monitoring. 
The actively heated fiber-optic (AHFO) method can estimate water content and dry density using temperature rise $\left(T_{t}\right)$. In this method, a cable or alundum tube can be heated for a specific time, and $T_{t}$ can be detected by the fiber-optic inside. Because of the sensor's sufficiently large length to diameter ratio, $T_{t}$ can be given by the solution of the line heat source:

$$
\begin{aligned}
T_{t}=T(t)-T_{0}=\frac{Q}{4 \pi \lambda} & {\left[\ln (t)+4 \pi R \lambda+\ln \left(\frac{4 K}{a^{2} c}\right)\right] } \\
t & \gg a^{2} / K
\end{aligned}
$$

where $T_{t}$ is the temperature rise $\left({ }^{\circ} \mathrm{C}\right)$, also known as the temperature characteristic value, $T(t)$ is the temperature of the heat source $\left({ }^{\circ} \mathrm{C}\right)$ corresponding to the heating time $t, T_{0}$ is the initial ambient temperature $\left({ }^{\circ} \mathrm{C}\right), Q$ is the heating power per unit length $\left(\mathrm{W} \cdot \mathrm{m}^{-1}\right), \lambda$ is the thermal conductivity of soil $\left(\mathrm{W} \cdot \mathrm{m}^{-1} \cdot \mathrm{K}^{-1}\right), R$ is the thermal resistance per unit length $\left(\mathrm{m} \cdot \mathrm{K} \cdot \mathrm{W}^{-1}\right)$ between the sensor and the soil wall, $K$ is the thermal diffusivity $\left(\mathrm{m}^{2} \cdot \mathrm{s}^{-1}\right)$ of the soil, $a$ is the outer diameter $(\mathrm{m})$ of the sensor, and $c=$ $1.7811=\exp (\gamma)$ where $\gamma$ is the Euler-Mascheroni constant $(=0.5772)$.

The thermal conductivity is the main factor determining the temperature rise. The thermal diffusion coefficient has a small contribution to the temperature rise. Equation(17) thus can be written in a compact form:

$$
T_{t}=\frac{m}{\lambda}+p
$$

where $m$ is a constant, $m=\frac{Q \ln \left(4 K t / a^{2} c\right)}{4 \pi}$, and $p=Q R$.

\subsubsection{Water content}

Firstly, we proposed an empirical function that can be used to quantify the relationship between the temperature characteristic value $\left(T_{t}\right)$ and the soil moisture (w) [Fig. 9(a)] [47]:

$$
T_{t}= \begin{cases}A \ln (w+B)+C & w \leq F \\ D w+E & w>F\end{cases}
$$

where $A, B, C, D$, and $E$ are fitting parameters, and
$F$ is the threshold mass water content. According to Tarnawski and Leong [48], the threshold volume water content of fine-grained soil is generally $0.05 \mathrm{~m}^{3} / \mathrm{m}^{3}-0.10 \mathrm{~m}^{3} / \mathrm{m}^{3}$.

Considering the complex parameters and the intangible threshold in (19), a semi-empirical model is put forward based on the Côté and Konrad model [49]:

$$
\lambda=\left(\lambda_{\text {sat }}-\lambda_{\text {dry }}\right) K_{e}+\lambda_{\text {dry }}
$$

where $K_{e}$ is the Kersten number, which is a function of the saturation $S_{r}, \lambda_{\text {dry }}$ is the dry thermal conductivity $\left(\mathrm{W} \cdot \mathrm{m}^{-1} \cdot \mathrm{k}^{-1}\right)$, and $\lambda_{\text {sat }}$ is the saturated thermal conductivity $\left(\mathrm{W} \cdot \mathrm{m}^{-1} \cdot \mathrm{k}^{-1}\right)$.

$K_{e}$ is given by

$$
K_{e}=\frac{\kappa S_{r}}{1+(\kappa-1) S_{r}}
$$

where $\kappa$ is an empirical parameter, which is related to the soil type.

$S_{r}$ can be expressed as

$$
\theta=n S_{r}=w \rho_{d} / \rho_{w}
$$

where $\theta$ is the volume water content $\left(\mathrm{m}^{3} / \mathrm{m}^{3}\right), n$ is the void ratio, $\rho_{d}$ is the dry density $\left(\mathrm{Mg} / \mathrm{m}^{3}\right)$, and $\rho_{w}$ is the density of water $\left(\mathrm{Mg} / \mathrm{m}^{3}\right)$.

According to (18), (20), (21), and (22), the relationship between $T_{t}$ and $w$ can be obtained:

$$
T_{t}=\frac{1}{A w /(1+B w)+C}+D
$$

where $\quad A=\frac{\kappa \rho_{d}\left(\lambda_{\text {sat }}-\lambda_{\text {dry }}\right)}{m n \rho_{w}} \quad, \quad B=\frac{\rho_{d}(\kappa-1)}{n \rho_{w}}$, $C=\frac{\lambda_{\text {dry }}}{m}$, and $D=p$ are fitting parameters, which are all constants.

The above (23) is suitable for unfrozen soil. When the soil temperature is below zero, the water in the soil solidifies into ice, and (23) is still applicable. However, it should be noted that the thermal conductivity of frozen soil $\left(\lambda_{\text {satf }}\right)$ varies with the different states of water in frozen soil [Fig. 9(b)]. Therefore, the values of fitting parameters $A, B$, and $C$ in (23) will be different. For unfrozen soil and frozen soil, the expressions of saturated thermal conductivity $\lambda_{\text {satu }}$ and $\lambda_{\text {satf }}$ are as follows: 


$$
\begin{gathered}
\lambda_{\text {satu }}=\lambda_{s}^{1-n} \lambda_{w}{ }^{n} \\
\lambda_{\text {satf }}=\lambda_{s}^{1-n} \lambda_{i}^{n-\phi_{u}} \lambda_{w}^{\phi_{u}}
\end{gathered}
$$

where $\lambda_{s}$ is the thermal conductivity of soil particles, $\lambda_{w}$ is the thermal conductivity of water, $n$ is the soil porosity, $\lambda_{i}$ is the thermal conductivity of ice and its value is $2.24 \mathrm{~W} \cdot \mathrm{m}^{-1} \cdot \mathrm{K}^{-1}$, and $\phi_{u}$ is the volume fraction of unfrozen water in the soil.

The empirical parameter $\kappa$ is different in both unfrozen soil and frozen soil. Therefore, the frozen soil calibration formula can be determined by the formula of unfrozen soil and the relationship between the calibration fitting parameters.

The parameters $A_{u}, B_{u}$, and $C_{u}$ are obtained by calibration test of unfrozen soil. For frozen soil, $\lambda_{\text {satf }}$ and $\kappa$ can be determined by using $A_{u}, B_{u}, C_{u}$, and measured $\left(w, T_{t}\right)$ before and after freezing, to further determine the fitting parameters $A_{f}, B_{f}$, and $C_{f}$ of frozen soil, thus obtaining the calibration formula of frozen soil and realizing the water content measurement in frozen soil.

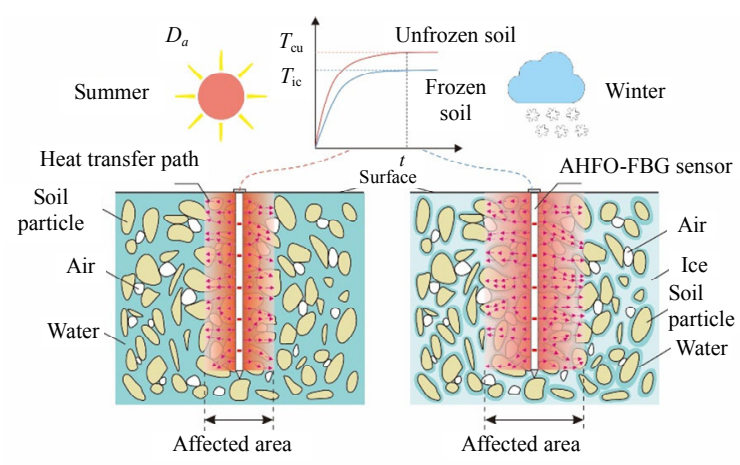

(a)

(b)

Fig. 9 Measurement principle of water content: (a) unfrozen soil and (b) frozen soil.

\subsubsection{Dry density}

Besides the water content, the thermal conductivity is also affected by dry density which can be described by the Singh and Devid model [Fig. (10)] [50]:

$$
\lambda=\frac{1.07 \lg w+d}{10^{3-0.6243 \rho_{d}}}
$$

where $d$ is a constant related to soil type.

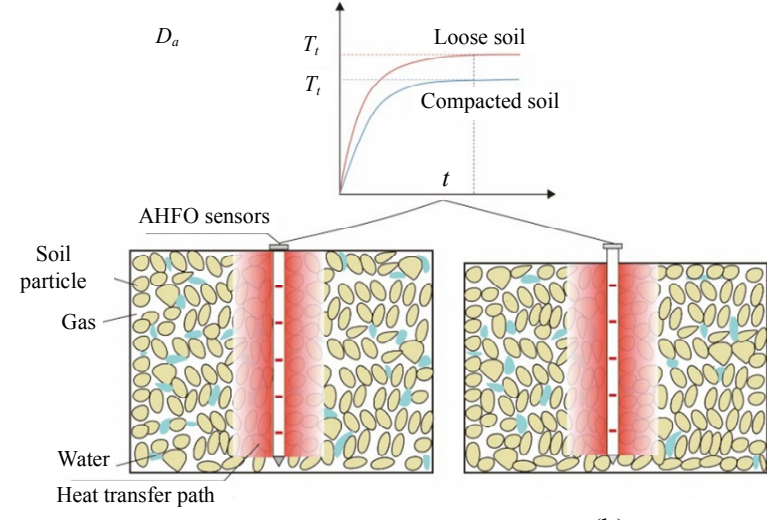

(a)

(b)

Fig. 10 Measurement principle of soil dry density: (a) loose soil and (b) compacted soil.

Combining (18) and (26), an exponential function can be obtained to describe the relationship between $T_{t}$ and $\rho_{d}$ :

where $a=3+\lg \left(\frac{m}{1.07 \lg \omega+d}\right)$, and $b=0.6243$.

\subsubsection{Humidity}

The humidity measurement is realized by the ORMOCER $^{\circledR}$-coated FBG (Fig. 11) [51]. When the ambient humidity changes, the volume of ORMOCER $^{\circledR}$ will change, resulting in the axial straining of the FBG. Since the ambient temperature may change in the process of humidity measurement, an uncoated FBG is employed for temperature compensation. Based on the above analysis, the formula for determining the humidity and temperature of the OR-coated FBG humidity sensor is

$$
\left\{\begin{array}{l}
\frac{\Delta \lambda_{1}}{\lambda_{1}}=K_{T 1} \Delta T+K_{\mathrm{RH}} \Delta R H \\
\frac{\Delta \lambda_{2}}{\lambda_{2}}=K_{T 2} \Delta T
\end{array}\right.
$$

where $\Delta T$ is the temperature variation, $K_{\mathrm{RH}}$ is the humidity sensitivity coefficient, $\Delta R H$ is the relative humidity variation, $K_{\mathrm{T} 1}$ and $K_{\mathrm{T} 2}$ are the temperature sensitivity coefficients of the OR-coated FBG and uncoated FBG sensing elements, $\lambda_{1}$ and $\lambda_{2}$ are the initial Bragg wavelengths, and $\Delta \lambda_{1}$ and $\Delta \lambda_{2}$ are the Bragg wavelength variations. 


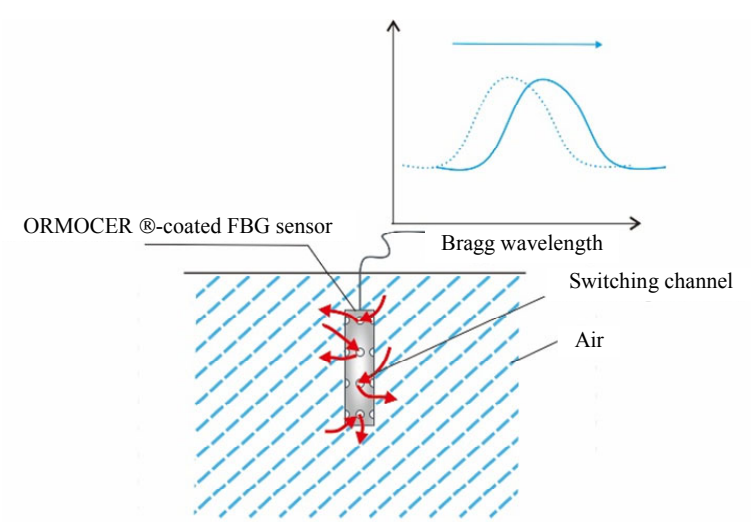

Fig. 11 Measurement principle of humidity.

A mathematical matrix of the OR-coated FBG humidity sensor used to calculate humidity and temperature is presented as follows:

$$
\left[\begin{array}{l}
\Delta T \\
\Delta R H
\end{array}\right]=\left[\begin{array}{cc}
0 & \frac{1}{K_{\mathrm{T} 2} \lambda_{2}} \\
\frac{1}{K_{\mathrm{RH}} \lambda_{1}} & -\frac{K_{\mathrm{T} 1}}{K_{\mathrm{T} 2} \lambda_{2}}
\end{array}\right]\left[\begin{array}{l}
\Delta \lambda_{1} \\
\Delta \lambda_{2}
\end{array}\right] .
$$

\section{R\&D of robust sensing cables}

As the "sensing nerve" in the monitoring of geological engineering, the optical sensing cables are both sensors and signal transmission medium, which should be both strong and sensitive to meet the requirements of multi-range and multi-parameter monitoring of geological engineering. For the DFOS monitoring of geological engineering, it is necessary to optimize the structure of the optical sensor cables according to the monitoring requirements, conduct performance testing and parameter calibrations through laboratory and field tests, and propose the installation and on-site protection methods.

\subsection{Structure and type of strain optical sensing cable}

Figure 12 shows five types of strain optical sensing cables developed by the authors' group.

(1) Thin sheathed strain optical sensing cable. It has the characteristics of a thin-layer sheath and good strain transmission, but the strength is low, as shown in Fig. 12(a). It is mainly used to package high-strength sensing optical cables, distributed pressure sensors, distributed stress sensors, etc.
(2) Low elastic modulus strain optical sensing cable. It has a soft tight jacket with low elastic modulus and good coupling with low-modulus materials as shown in Fig. 12(b). It is mainly used for strain monitoring in indoor and outdoor soil model tests.

(3) High strength strain optical sensing cable. It adopts metal stranded wire tightly wrapped structure, which has the characteristics of high strength, high elastic modulus, and good straightness, as shown in Fig. 12(c). It can be used for strain and deformation monitoring of rock mass and concrete structures.

(4) High stability strain optical sensing cable. It adopts integrated packaging with high-temperature resistance and low creep materials, which has the characteristics of high-temperature resistance and high long-term stability, as shown in Fig. 12(d). It is mainly used for monitoring the creep and long-term deformation of surrounding rocks.

(5) Ribbon strain optical sensing cable. It is encapsulated into a ribbon-type cable with metal sheets, fiber cloth, etc. for strain sensing, which is easy to be installed on the surface by welding or pasting, as shown in Fig. 12(e). It is mainly used for the monitoring of structures such as pipelines, tunnels, and steel pipe piles.

The sensing cables for distributed temperature sensing (DTS) and distributed vibration sensing (DAS) were designed for applications [20, 52].

\subsection{Fatigue characteristics}

Under the condition of long-term tension, the materials of the optical cables will show recoverable elastic deformation and unrecoverable plastic deformation. There will be relative displacement between the various buffers of the optical cable. The fatigue characteristics of the optical sensing cable directly affect its long-term stability. The authors' group developed a device to evaluate the fatigue characteristics of the sensing optical cable according to the strain decay curves after low cyclic tension. 


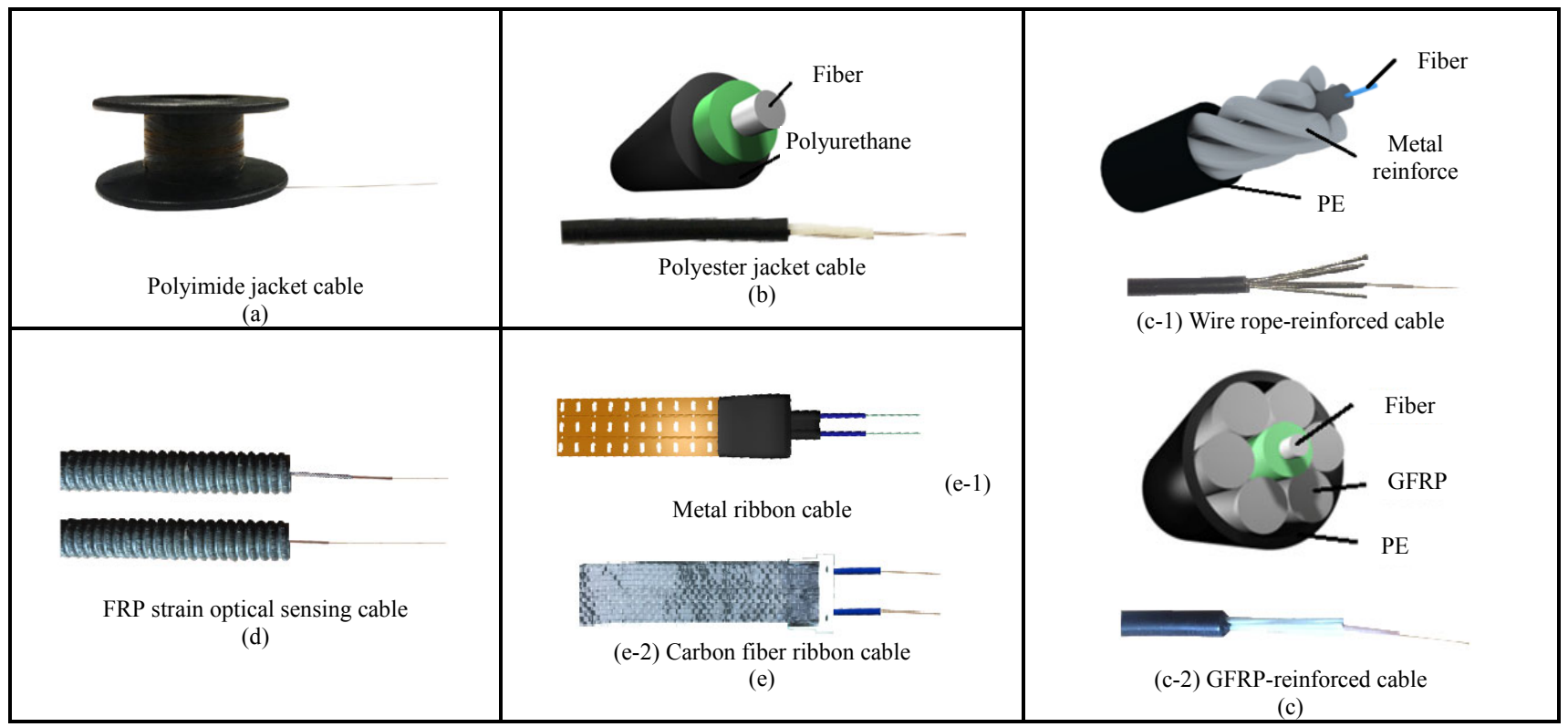

Fig. 12 Five types of strain optical sensing cables: (a) thin sheathed strain optical sensing cable, (b) low elastic modulus strain optical sensing cable, (c) high strength strain optical sensing cable, (d) high stability strain optical sensing cable, and (e) ribbon strain optical sensing cable.

The cable strain decayed exponentially, and the decay process involved quick decay, slow decay, and stabilization stages, as shown in Fig. 13. The sensing cables with different jackets differed in the amount and rate of decay. For the same cable, the strain decay increases with the initial strain and tensile frequency. As the unstrained period increased, the initial strain levels of the strain decay curves approached those of the first cyclic elongation. The proposed cyclic fatigue testing method can be used to identify the fatigue characteristics of distributed strain sensing cables with different jackets and can serve as a reference in assessments of cable performance during long-term use [53].

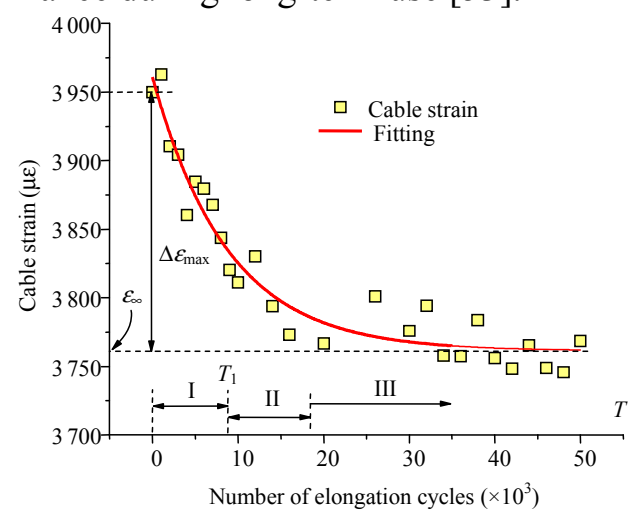

Fig. 13 Strain decay curve of the tested PU-jacketed sensing cable at a tensile frequency of $3 \mathrm{~Hz}$.

\subsection{Temperature sensing performance}

To compare the temperature sensing performances of different cables, the authors' team conducted a comparison test in a walk-in constant temperature and humidity laboratory by using BOTDR [54]. Figure 14 shows the relationship curve between the Brillouin frequency shift and temperature of different optical sensing cables. It can be seen that the temperature coefficients of the optical cables with variant jackets are different. The temperature coefficient of some optical cables will change at a certain temperature. Therefore, when the optical sensing cables are used in high-temperature

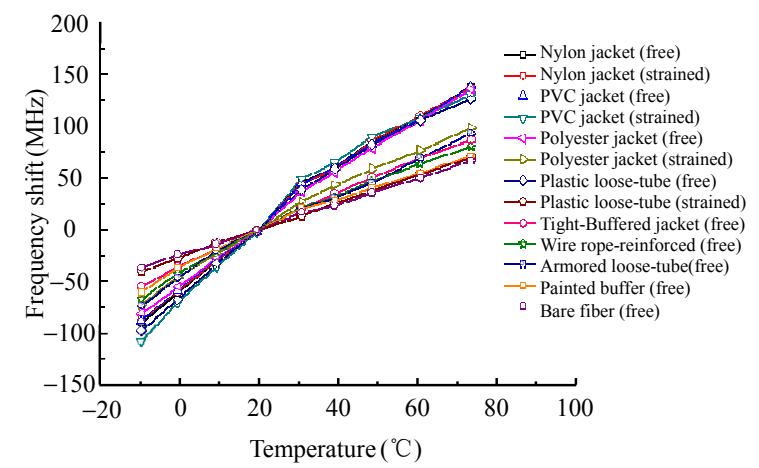

Fig. 14 Frequency shift-temperature curve of different optical cables. 
environments, the high-temperature-resistant cables should be developed, or the test results should be calibrated and corrected.

\subsection{Multi-range deformation measurement}

Because the measurable strain range of quartz optical fiber is generally less than $\pm 2.0 \%$ to realize distributed monitoring of large deformation of rock and soil, a specific encapsulation of the sensing cable and the installation method should be adopted to achieve multi-range deformation monitoring according to the characteristics of rock and soil deformation. In summary, there should be three solutions [20]:

(1) For the deformation monitoring with a measuring range less than $0.5 \%$, it can be realized by using FBGs and optical sensing cables with fully contact installation, with which the FBG sensors and the sensing cables are directly attached on the surface or embedded in the measured object, as shown in Fig. 15(a).

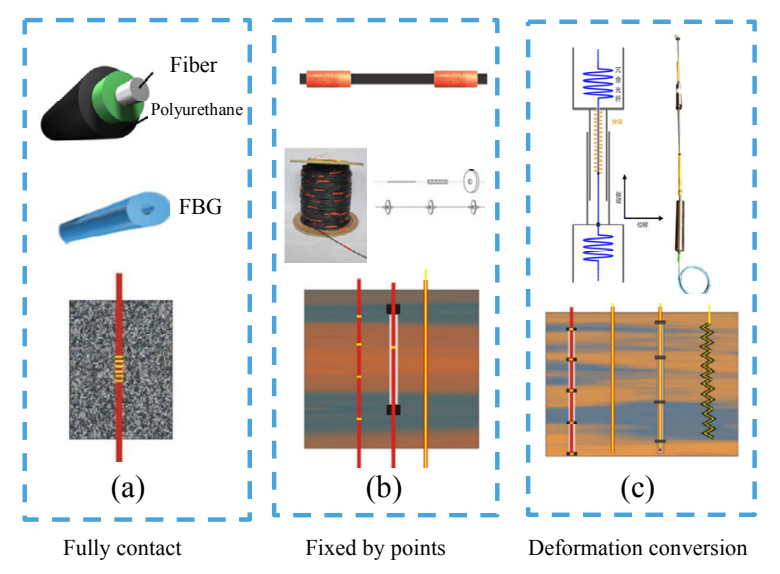

Fig. 15 Principle of deformation sensing with different measuring ranges: (a) $0-0.5 \%$, (b) $0.5 \%-2 \%$, and (c) $2 \%-50 \%$.

(2) For the deformation monitoring with a measuring range between $0.5 \%$ and $2 \%$, the optical sensing cable fixed by points can be used to achieve homogeneous deformation, as shown in Fig. 15(b). The core is fixed with the jacket by points, at which the sensing cables are fixed with the measured object. Beyond the fixed point, the fiber core is free and is loosely sleeved. In this way, different strain ranges can be achieved by adjusting the distance between the fixed points.

(3) For the deformation monitoring with a measuring range between $2 \%$ and $50 \%$, it can be realized by encapsulating a multi-point displacement meter with a spring or other deformation conversion modes, as shown in Fig. 15(c).

\subsection{Actively heated fiber-optic cable}

According to the principle of heat exchange, when using the DTS technology to monitor water and seepage fields in geological engineering, the actively heated fiber-optic cables are the basic sensing element. Figure 16 shows the structure of two sensing cables, the carbon-fiber heated cable (CFHC) and the metal-net heated cable (MNHC) [20, 22].

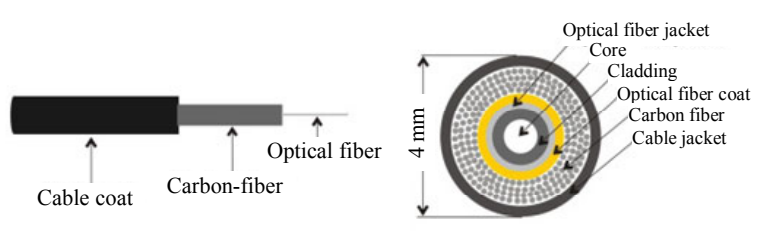

(a)
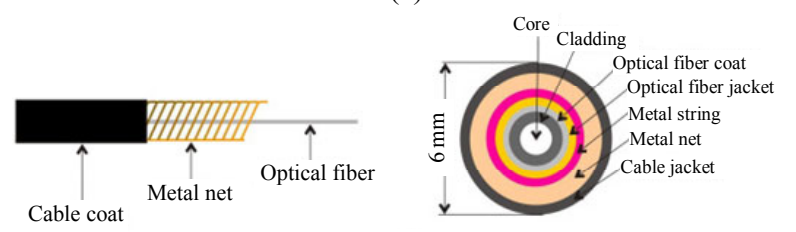

(b)

Fig. 16 Optical cable structure of CFHC and MNHC: (a) carbon fiber heated cable and (b) metal net heated cable.

CFHC consists of a multimode optical fiber, carbon-fibers, and a cable jacket. CFHC has large resistance, low required voltage, and strong corrosion resistance. CFHC is suitable for short-distance $(<500 \mathrm{~m})$ distributed monitoring of soil moisture. The structure of MNHC is similar to that of CFHC. However, MNHC is heated by the metal net. MNHC has the characteristics of low resistance, and long-distance and low-temperature value, which is more suitable for long-distance and large-area soil moisture monitoring.

Because the optimal spatial resolution of DTS is 1 meter, for moisture monitoring with high spatial 
resolution, the heated cables can be wrapped around a tube or a bar to form a heated sensing tube. Figure 17 shows the structure and the photo of the carbon fiber heated sensing tube (CFHST for short) wrapped by CFHC [22].

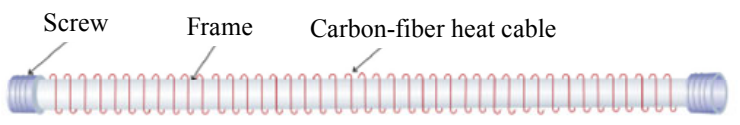

(a)

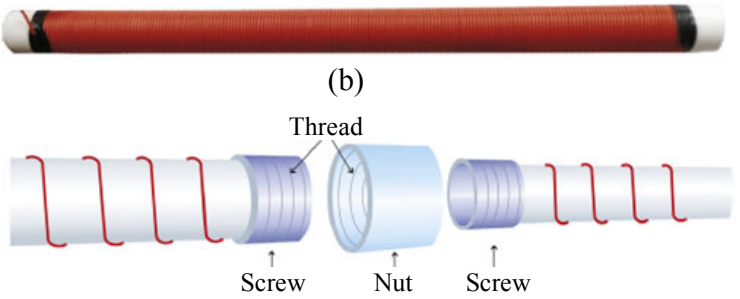

(c)

Fig. 17 Schematic diagram of carbon fiber heated sensing-tube: (a) CFHST structure with screw cap and CFHC wingding, (b) the completed CFHST, and (c) CFHST screwed-on connection.

\section{FOS-based geo-engineering monitoring systems}

To apply the DFOS technology to geo-engineering monitoring, besides the development of special fiber optic sensors and sensing cables, another important task is to develop advanced monitoring systems. A distributed fiber optic monitoring system for geo-engineering is generally composed of the data acquisition subsystem, the data transmission subsystem, the data analysis subsystem, the decision-making subsystem, etc. Each subsystem is interrelated and indispensable, and each part is an organic part of the whole system. Due to the low degree of standardization of the fiber optic sensors, different types of sensors generally require specific data acquisition subsystems. Thus, once the sensing technology is selected, the corresponding data acquisition and processing technique is determined. That means the optimal placement of the sensors and the signal processing and analysis part are two key issues of a fiber optic monitoring system. In engineering practices, the monitoring information of a certain object obtained by fiber optic sensors is sent to the monitoring center through the data acquisition and transmission subsystems for data processing and assessment. On this basis, the stability state of the object under monitoring is evaluated. If the detected key parameters exceed the predetermined thresholds, the relevant management agents will be informed timely through the short message (SMS), E-mail, and other means, to take corresponding emergency measures to avoid significant loss of personnel and property.

As shown in Fig. 18, there are four subsystems in a distributed fiber optic monitoring system, i.e., the data acquisition subsystem, the data transmission subsystem, the data analysis subsystem, and the decision-making subsystem [55]. The basic functions of each subsystem are:

(1) The establishment of the data acquisition subsystem mainly involves the selection of various fiber optic sensors and the sensing cables, the selection of suitable modulation methods, and then the determination of the topology of fiber optic sensors. On this basis, the sensor layout modes are selected (for example, the surface adhered or internal embedded type). Finally, how to realize the modulation signal demodulation and how to establish the field monitoring and control station will be considered. The terminal sensors are mainly distributed fiber optic sensors with different functions (including quasi-distributed), which are used for monitoring deformation field, temperature field, and seepage field and stress field of rock and soil mass.

The DFOS technology can be categorized into intensity modulation, phase modulation (interferometric), wavelength modulation, frequency modulation, and polarization modulation. Correspondingly, there are several demodulation technologies. Different types of modulation and demodulation instruments are combined to construct a DFOS monitoring system. By using the virtual instrument technology, the demodulator is automatically controlled, parameters are set and data 
are collected and stored by the controlling PC. Data acquisition should be remote, networked, and automated, and be combined with the database technology to realize local storage of data [56].

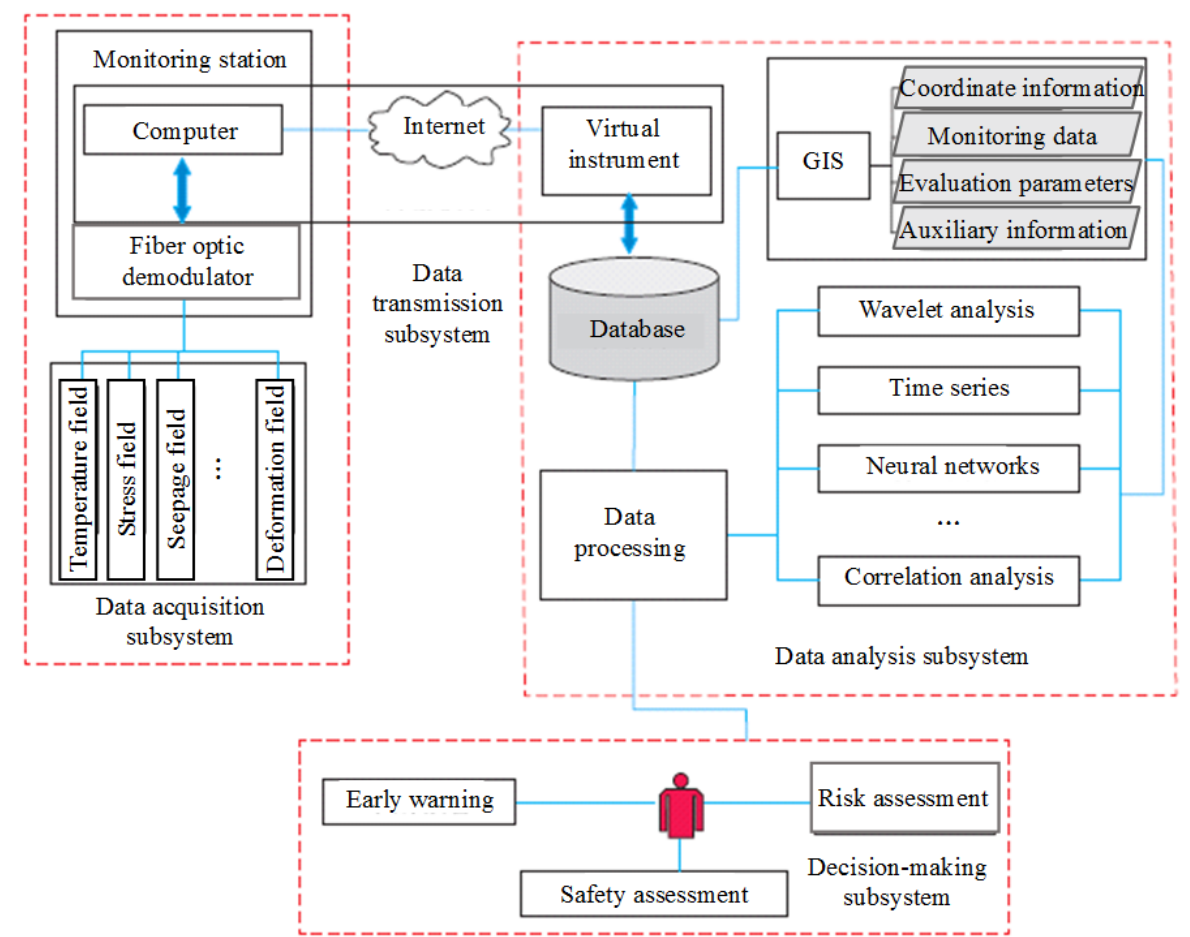

Fig. 18 Illustration of the geoengineering monitoring system.

(2) The data transmission subsystem connects the data acquisition subsystem and the data analysis subsystem, including the communication and data exchange between the Internet or wireless network and the remote terminal processor, and therefore the storage structure and mode of massive real-time data will be set. The data transmission subsystem mainly consists of three parts: the first part is the transmission from the signal modem to the sensor elements; the second part is the transmission from the signal modem to the data analysis subsystem; the third part is to quickly transmit the monitoring analysis results to the clients. The former is generally realized by wire transmission. However, with the continuous improvement of smart sensor technologies, the use of wireless transmission will be more and more preferred. In recent years, the employment of wireless, Internet, and communication satellites to transmit signals has been very popular. Since the DFOS systems for geo-engineering monitoring are often installed in very harsh local environments, it is hard for people to reach, so the use of wireless transmission should be the trend. Some systems already have a data analysis system installed in the signal modem, in which case the second part of the transmission is not required. Finally, there are many ways to quickly convey the monitoring analysis results to users, among which it is an inevitable trend to send the monitoring results and early warning signals to mobile phones, computer terminals, and public service platforms through Internet.

(3) The data analysis subsystem is the core part of the monitoring system, which is based on software technologies, such as geographic information system (GIS) and database. This subsystem is in charge of mass monitoring data processing (including information query, contrast, and extract.), management, validity analysis, selection of monitoring parameters, construction of the database, graphical presentation, etc.

With the improvement of the monitoring 
technologies, the diversification of monitoring information has been achieved. The management of monitoring data is not only the storage, query, and display of monitoring data, but interactive three-dimensional management combined with the spatial geography. Therefore, the management of data must enable the remote processing of updated data acquisition and direct visualization and can simulate all kinds of emergencies combined with virtual reality, to distinguish various events for the influence of engineering safety. The realization of these goals greatly increases the geoengineering monitoring level.

Especially for the massive fully distributed monitoring data, they often need to be processed, including denoising, smoothing, coordinating, and subtracting. More importantly, it is necessary to identify, capture, and display abnormal points and areas of the monitoring data, and to get evaluation conclusions or issue prediction and early warning of the objects under monitoring, which all require the data analysis subsystem to complete. In recent years, a series of "soft computing methods", including fuzzy logic, artificial neural network, genetic algorithm, wavelet analysis, machine learning, and other computational intelligence technologies, have been developed rapidly. That makes it possible to conduct large-scale computing reasoning and parallel inference and provides a solid theoretical basis for health diagnosis in geoengineering.

(4) The decision-making subsystem has the functions of report output, safety evaluation, and the corresponding pre-disaster warning and forecasting.

According to the results of monitoring and analysis, users can make corresponding decisions and give timely warning to the hidden dangers of engineering safety.

In the decision-making process, the combination of traditional and modern methods is needed, such as mathematical statistics, numerical analysis, expert system, rough set theory, extension engineering theory, and dynamic fingerprint technique. In this way, the stability or health conditions of the object to be measured can be evaluated with high reliability. In addition, comprehensive analyses and parametric inversion of the calculation model can be conducted. Combined with the geological information, field observations, abnormal signals, and other related data, the forecasting of potential hazards can be realized [56].

Finally, appropriate emergency treatment measures should be taken, such as setting up warning areas, soil reinforcement, unloading, and evacuation, to minimize the risk of the loss of human life and properties.

From the point of view of engineering safety monitoring demand and technology development, distributed monitoring is the development trend of engineering monitoring.

In the future, combined with the GIS and database technology, the wireless data transmission technology enables the setup of monitoring networks at the engineering level, city level or regional level, and even nationwide level. In these monitoring networks, monitoring information center, fiber optic sensing network, and wired and wireless transmission serve as the core, the monitoring optical fiber network main entity, and the carrier, respectively. By this means, the normal operation of geo-engineering infrastructures can be wired and wireless transmission for the media monitoring system will run to the health of the geological and geotechnical engineering, thus providing a reliable guaranteed.

\section{Applications to geotechnical engineering monitoring}

In recent years, the optical fiber sensing technology has been widely used in the field of geo-engineering monitoring and has been rapidly developed with its unique advantages. In the detection and monitoring of foundation engineering, especially the detection of pile foundations, distributed optical fiber sensing technologies such as 
BOTDR/A and BOFDA can be used to perform fully distributed detection of the strain, force, and flexure status of the pile body [4, 57-59]. In tunnel and underground engineering structural health monitoring, DFOS has prominent advantages, unveiled in a series of research $[6,8,60-65]$. In the deformation and stability monitoring of supporting structures such as foundation pits and retaining walls, the practice has proved that the distributed optical fiber sensing technology is feasible and effective, and has obvious advantages [66-68]. Besides, the distributed optical fiber sensing technology shows broad application prospects in monitoring the deformation and stability of artificial soil filling, excavation of slopes, highway and railway sub-grades, and river embankments [19, 20, 69-71].

This section briefly introduces the applications of the distributed optical fiber sensing technology in engineering of piles and tunnels.

\subsection{DFOS test system of the foundation pile}

The DFOS test system of the foundation pile includes four subsystems: pile measurement, data collection, transmission and storage, and data processing and analysis. As shown in Fig. 19, the force and deformation characteristics of the pile are sensed by the optical sensing cable laid on the pile. The distributed information such as temperature, stress, and strain of the pile is obtained by the data collection system. The information is connected to the network through the data transmission line, and it is stored on the local hard disk or network hard disk. Finally, the results are obtained by the data processing and analysis subsystem.

For various types of foundation piles, the installation and layout methods of the sensing optical cables are different, as shown in Fig. 20. For precast piles, the sensing optical cables need to be installed in various parts of the precast pile body by a special laying process to ensure that the strain of the sensing optical cables is consistent with the deformation of the pile. For cast-in-place piles, just tie the metal base optical cable to the steel cage. For steel pipe piles, the metal base ribbon optical cable or carbon fiber composite base optical cable can be installed on the surface of the steel pipe by welding and cementing.

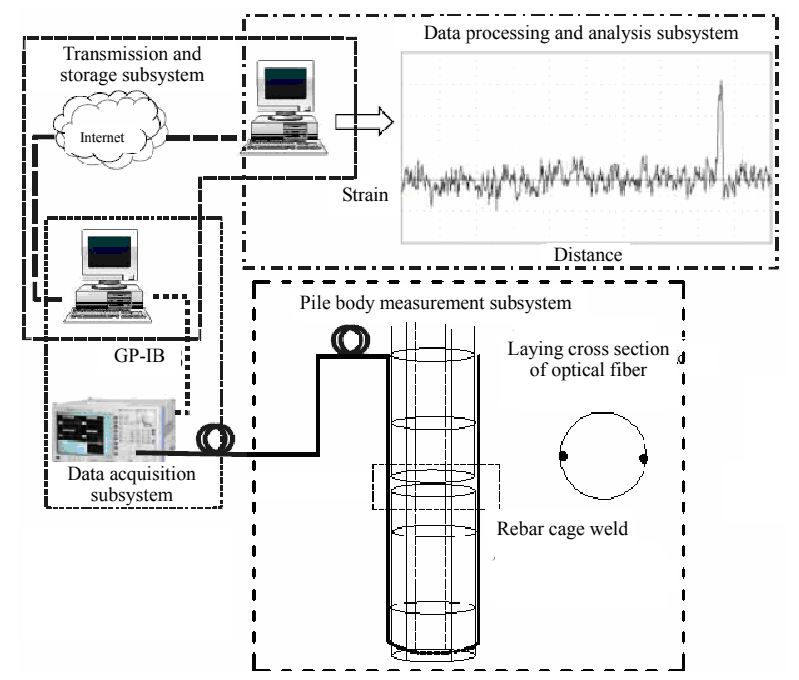

Fig. 19 Schematic diagram of the DFOS test system of the foundation pile.

The distributed optical fiber sensing technology can be applied in static load tests of various pile foundations, pile driving monitoring, and horizontal deflection monitoring of anti-slide piles. When the pile body is deformed under force, the built-in sensing optical cable will deform in coordination with the pile body. Then, the distributed strain sensing technology can test the entire strain distribution of the pile body. This method can test the fine distribution law of pile body strain in the whole section of the pile body and analyze the force behavior of the pile body (axial force, side friction resistance, pile compression, etc.) and the pile quality (elastic modulus, etc.), measure the bearing capacity of the pile foundation, and provide data reference for the optimization design of the pile foundation. Figure 21 shows the test results of the BOTDA of the pretensioned spun high strength concrete (PHC) piles under the horizontal load. 


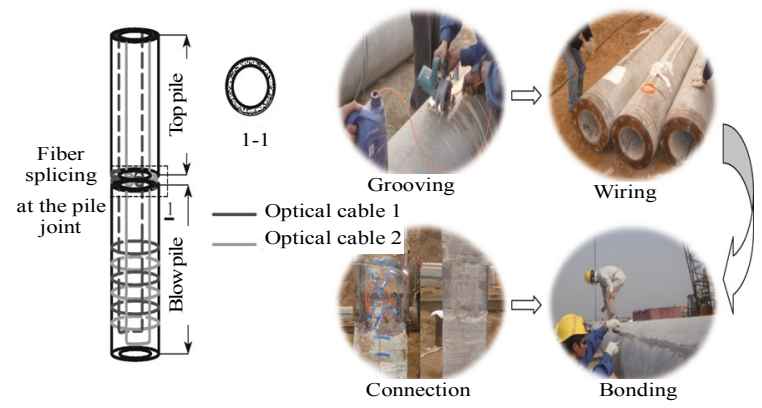

(a)

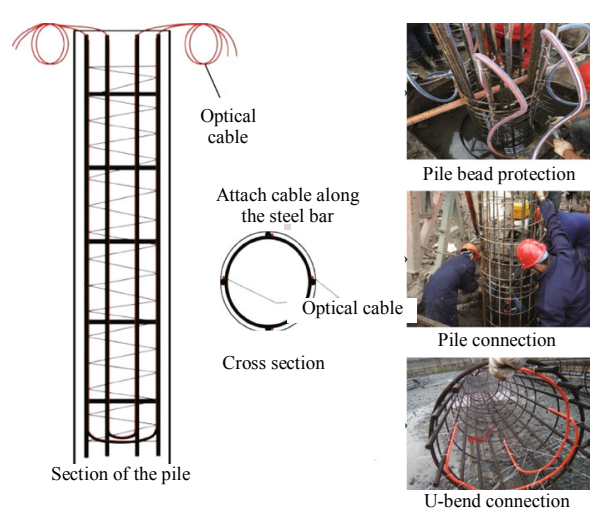

(b)

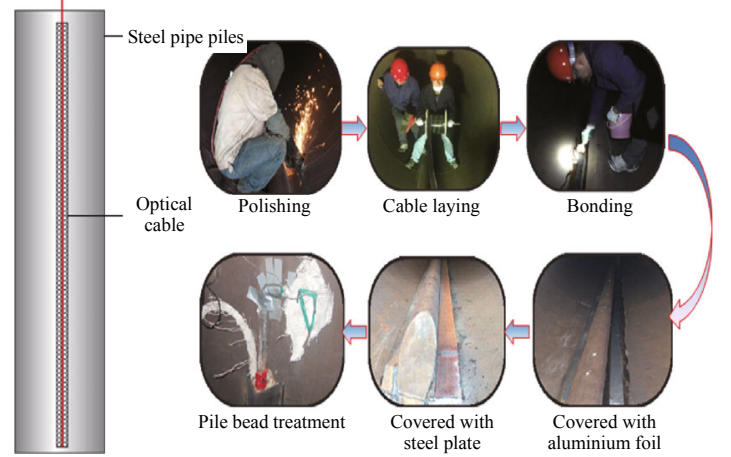

(c)

Fig. 20 Layout of cables on the foundation pile: (a) prefabricated piles, (b) cast-in-place piles, and (c) steel pipe piles.

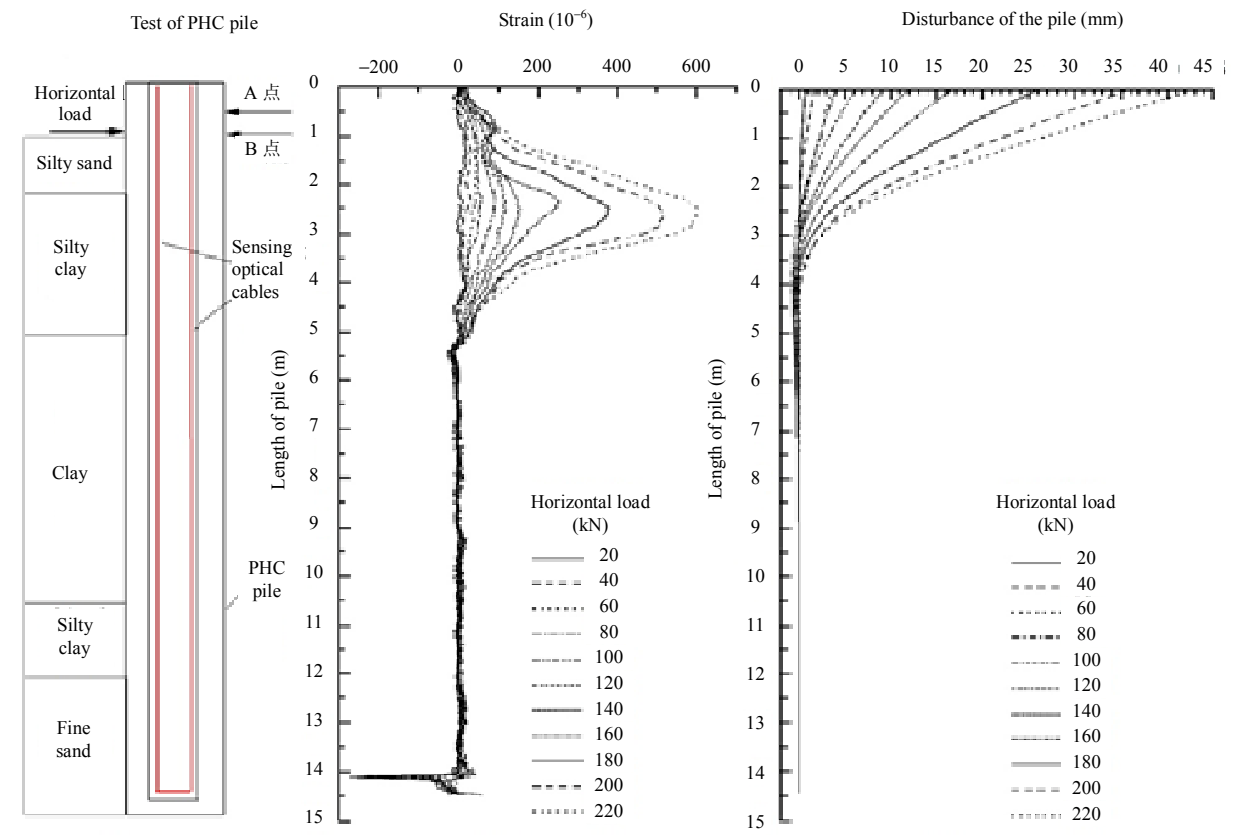

Fig. 21 Test results of the BOTDA of pile body under horizontal load.

\subsection{Research on the optical fiber monitoring technology in tunnel}

Tunnel construction is generally divided into three types: open-cut, cover-cut, and shield methods.
The main monitoring contents of the open-cut tunnel include anti-slide pile monitoring, anchor cable and anchorage system monitoring, top beam and waist beam monitoring, main supporting structure 
monitoring, main body side displacement fiber can be obtained accordingly, so the monitoring, ground surface deformation monitoring, and tunnel deformation monitoring. The optical fiber can be implanted into the soil around the anti-slide pile, top beam, waist beam, anchor cable, and tunnel, and connect each part in series to form a system. DFOS technology is used to comprehensively monitor the deformation of the supporting system and the surrounding soil. For some key points, the FBG sensing technology can be used to measure in real time, as shown in When any part is deformed, the strain of the optical

Fig. 22(a).

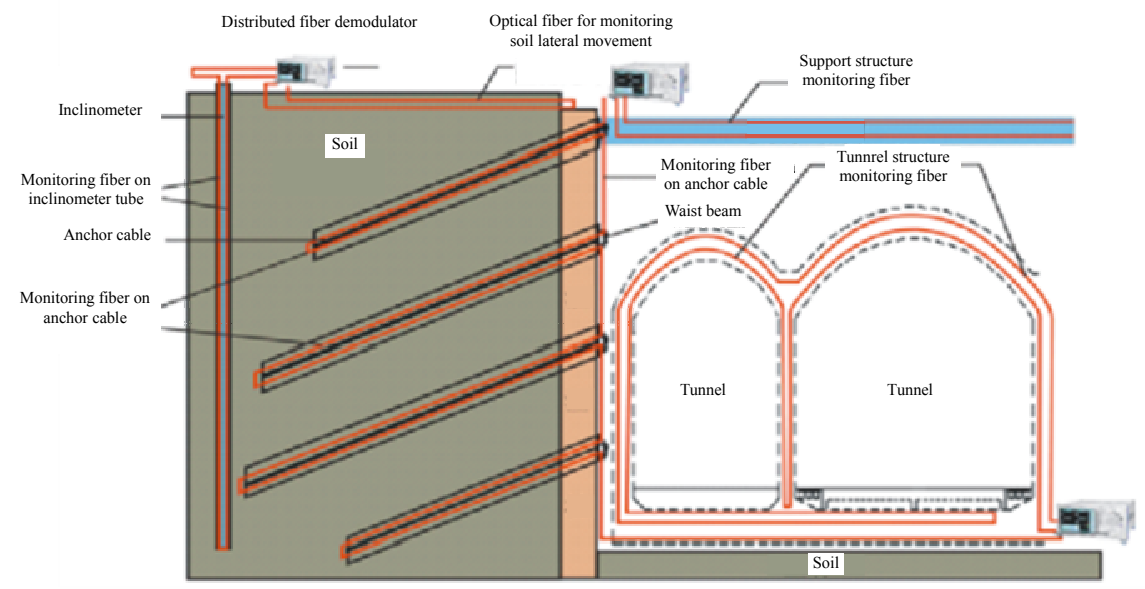

(a)

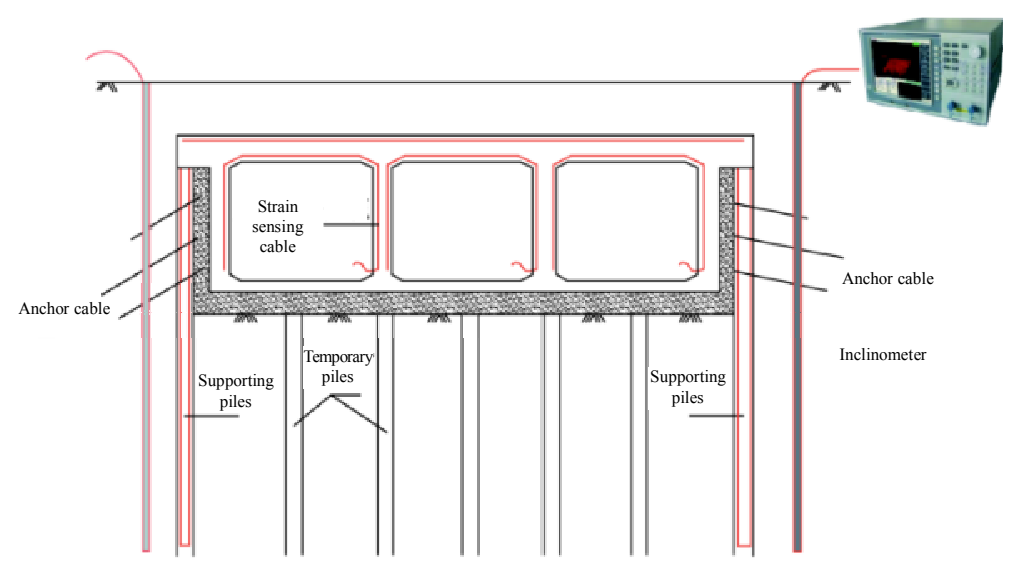

(b)

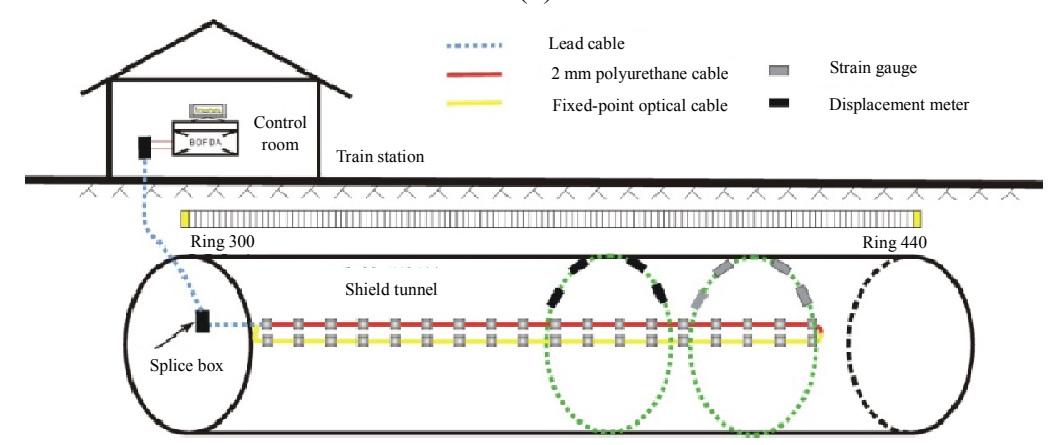

(c)

Fig. 22 Schematic diagram of tunnel fiber monitoring: (a) optical fiber monitoring of open-cut tunnel, (b) optical layout in cover-cut section, and (c) optical fiber monitoring of shield tunnel. 
The monitoring of the cover-cut tunnel mainly includes the stress distribution of the supporting pile, the deformation of the roof, the overall stability of the tunnel structure, and the monitoring of the surrounding soil deformation. The overall layout scheme of cable is shown in Fig. 22(b).

The shield tunnel monitoring mainly includes the uneven settlement of the tunnel, the convergence of the ring structure, the deformation of the segment structure, and the expansion and contraction of the segment joints. The layout of the cable is shown in Fig. 22(c). The opening, closing, and dislocation deformation of segment joints and structural seams are the main sources of deformation of shield tunnels, which need to be monitored. Generally, two methods are adopted: the first method is to fix the strain sensing optical cable on the two sides of the contact seam or the tube piece. When the joint is opened or closed, the strain sensing optical cable will stretch or return. And the optical cable will undergo strain changes, and the integral of the strain and the fixed-point distance is the change in the width of the joint. The second method is to use the FBG displacement sensors, which are installed on both sides of the joint to realize the joint opening and closing deformation monitoring. Figure 23 shows the BOFDA monitoring results of the expansion and contraction of the joints of the shield tunnel segments.

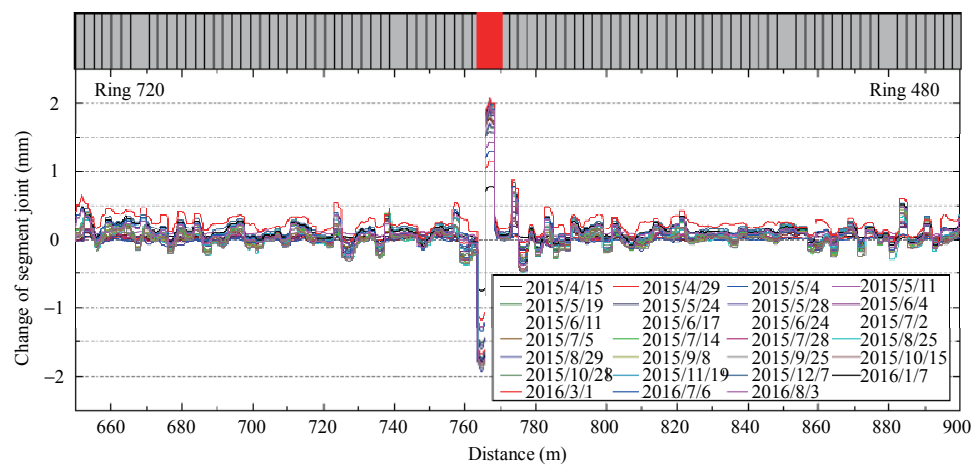

Fig. 23 BOFDA monitoring results of the expansion and contraction of the joints of the shield tunnel segments.

\section{Applications to geo-hazards monitoring}

Monitoring plays a key role in the risk assessment, prediction, and early warning of the geological hazard. In recent years, the optical fiber sensing technology has shown its advantages in geological hazard monitoring and early warning $[67$, 72, 73]. The monitoring technology has been successfully applied to monitoring geological hazards such as landslides, ground collapse, ground subsidence, and ground fissures [21, 74-81]. In geological hazard monitoring, deformation of rock and soil mass and water distribution are two very important monitoring contents. Therefore, this section briefly introduces two kinds of optical fiber monitoring technology that are suitable for monitoring land subsidence deformation and water content distribution.

\subsection{Borehole full-section optical fiber monitoring technology}

The borehole full-section optical fiber monitoring is to lay fiber-optic sensing cables or sensors in the borehole to form a distributed (including quasi-distributed and fully distributed) multi-fields and multi-parameters optical fiber comprehensive monitoring system. This monitoring technology can monitor quantitatively the distribution of borehole deformation, groundwater level, temperature, water content, pore water pressure, and so on, to get the change rule of multi-parameters of borehole full section geological body. 
The system consists of four parts: (1) monitoring module, (2) signal modulation and demodulation module, (3) signal transmission and data analysis module, and (4) evaluation module. The monitoring module mainly includes the ground drilling, the layout and installation of sensing optical cable and sensor, and the establishment of monitoring station; the signal modulation and demodulation module mainly includes a modem, field data acquisition, and storage. Signal transmission and data analysis module mainly involves the communication, data exchange, and data processing analysis between the Internet or wireless network and remote terminal processor; the evaluation module mainly includes report output, multi-field potential evaluation, and early warning prediction, as shown in Fig. 24.

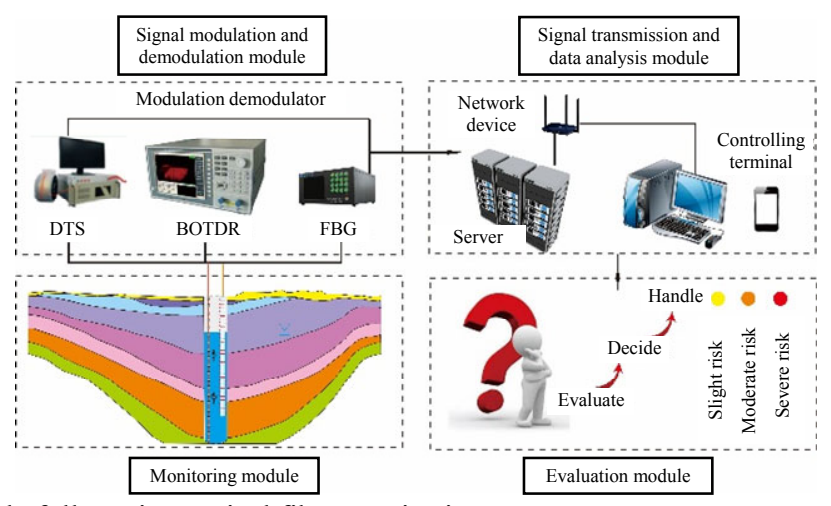

Fig. 24 Composition of borehole full-section optical fiber monitoring system.

To demonstrate the application of the borehole full section optical fiber monitoring system, this section takes the optical fiber monitoring of Suzhou Shengze land subsidence as an example to introduce the monitoring efficacy of this technology.

The thickness of the quaternary stratum in the Suzhou area is about $180 \mathrm{~m}$. The site of the test borehole is selected in the sports ground of
Shengze middle school in Suzhou. The diameter of the monitoring hole is $129 \mathrm{~mm}$ and the depth is $200 \mathrm{~m}$. The optical fiber monitoring system of the whole section of the borehole is shown in Fig. 25. The initial value was measured after the consolidation of the borehole backfill. The monitoring cycle was once every 3 months to 4 months.

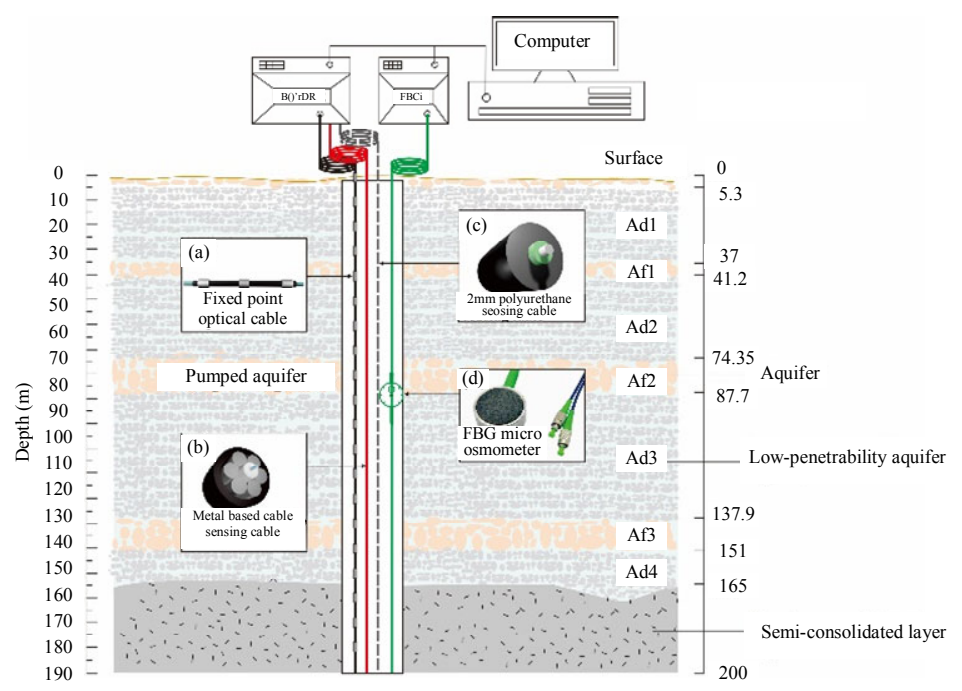

Fig. 25 Borehole full-section optical fiber monitoring for ground subsidence drilling in Shengze, Suzhou. 
Figure 26 shows part of the results of the full section optical fiber monitoring of the ground settlement borehole. In the range of $42.35 \mathrm{~m} \mathrm{-}$ $74.35 \mathrm{~m}$ and $87.7 \mathrm{~m}-111.5 \mathrm{~m}$ (that is, the two impermeable layers Ad2 and Ad3 adjacent to Af2), the fiber shows obvious compressive strain, and the strain increases gradually with time. It shows that the main compression strata are the impermeable layers $\mathrm{Ad} 2$ and $\mathrm{Ad} 3$ adjacent to the main pumping layer, and are still under

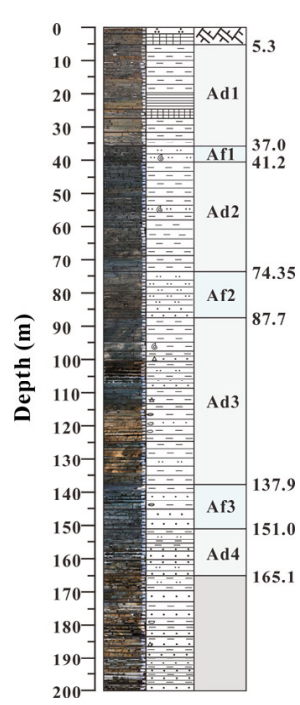

(a)

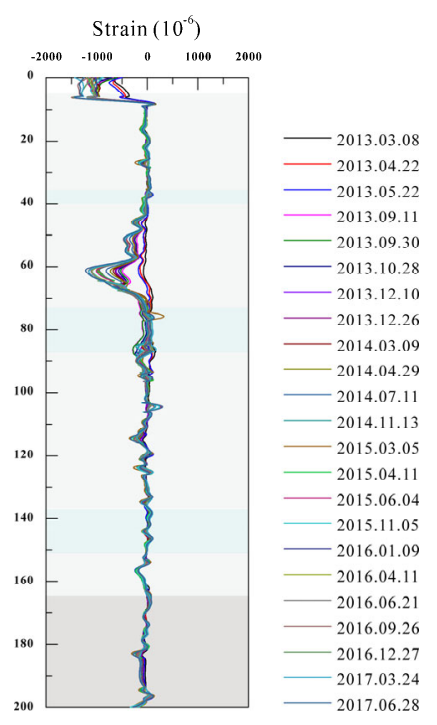

(b)

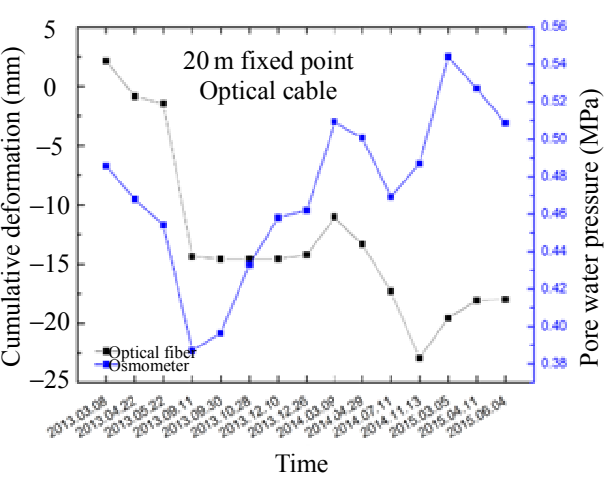

(c)

Fig. 26 Partial results of full section optical fiber monitoring of ground settlement borehole in Shengze, Suzhou: (a) plane map of stratum, (b) optical fiber monitoring data, and (c) relationship between cumulative deformation of $5.3 \mathrm{~m}-164.1 \mathrm{~m}$ formation and pore pressure.

\subsection{Optical fiber monitoring technology of moisture content}

The distribution and degree of water content in the soil are the significant factors affecting the stability of the soil. Geological hazards such as landslide, debris flow, collapse, land subsidence, and geotechnical engineering problems (including foundation pit instability, retaining wall collapse, and tunnel leakage) are closely related to the soil moisture field. Therefore, the monitoring of the water content in soil is of great significance for mastering the engineering properties of soil, preventing geological hazards, and solving various geotechnical engineering problems.

In recent years, the distributed optical fiber compression.

This monitoring result was consistent with the monitoring results of the layerwise marks. However, the results of the optical fiber monitoring were more detailed, which reflected the effectiveness and advanced nature of the borehole full section optical fiber monitoring technology for monitoring the ground settlement and deformation. temperature measurement technology based on the active heating optical fiber (AHFO) was used to measure the temperature of soil with different moisture contents, establish calibration curve, and then calculate the moisture content of soil according to the measured temperature change value. This method has been successfully applied to a large number of laboratory tests [23, 82-85]. Furthermore, some scholars have also tried to apply this method to the monitoring of soil moisture content in situ, and some achievements had been made [47, 86-88].

Distributed optical fiber monitoring of the water content in the soil is realized by measuring the size and distribution of soil moisture content. The 
authors' team has developed two kinds of optical fiber sensors (cables) with active heating function based on the FBG and DTS temperature measurement technology. The special optical fiber sensors (cables) are implanted into the soil to obtain the time history curves of active heating and temperature rise in the soil with different moisture contents and determine the temperature characteristic value $\left(T_{t}\right)$ of the soil. Furthermore, by establishing the relationship between $T_{t}$ and volume moisture content in the soil, the size and distribution of water content in the soil were measured to realize the distributed monitoring of water content in the soil.

In practical application, the heated FBG sensor or DTS sensing optical cable was installed in the measured soil by layered embedding, inserting, or drilling. Especially, in the way of borehole embedment, it was necessary to backfill the earth material in the borehole and ensure that the optical fiber measuring tube was tightly packed with the surrounding soil and no space was left. The soil moisture field monitoring system based on the FBG and DTS was generally composed of heating, sensing, data processing, transmission, and analysis subsystems. Figure 27 shows a portable heating DTS moisture meter developed by Suzhou Nanzhi Sensing Technology Co., Ltd.

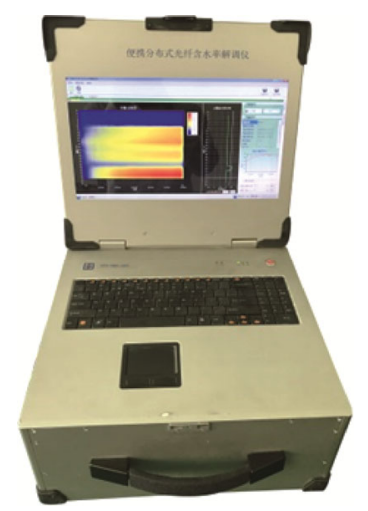

Fig. 27 Portable heating DTS moisture meter (developed by Suzhou Nanzhi Sensing Technology Co., Ltd.).

Figure 28 shows the variation of soil profile moisture content measured by CFHST during dewatering of a foundation pit. It can be seen that the groundwater level has been falling continuously during the whole test process, from $9.81 \mathrm{~m}$ at the beginning to $14.08 \mathrm{~m}$ at the end. The moisture content of the topsoil layer was affected by weather, and the influence depth was about $4 \mathrm{~m}$. The test results were very clear. At present, this technology has been widely used in the loess water field and Yangtze River Dike Seepage projects.

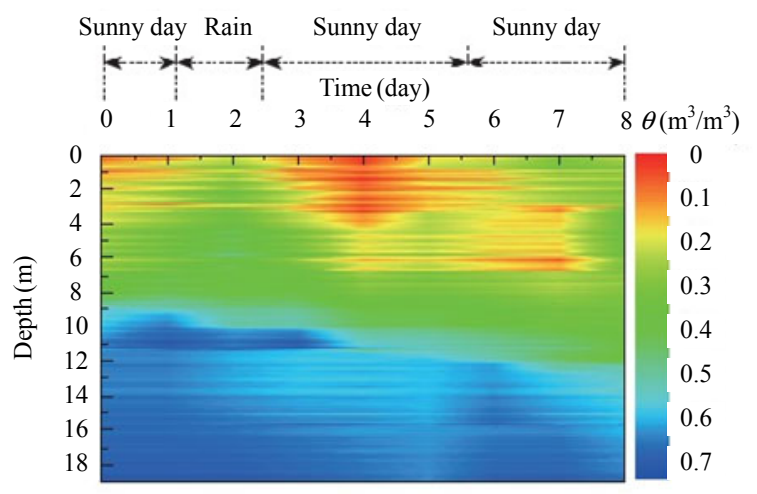

Fig. 28 Moisture content of soil profile during dewatering of a foundation pit.

\section{Prospects and conclusions}

With the continuous development of engineering activities to the deeper underground space, the engineering geological and hydrogeological conditions encountered are becoming more and more complex, and the geo-environment is becoming harsher and harsher. Therefore, there is an increasing requirement for robust sensing technologies and systems. In the past 10 years, the development of the distributed fiber optic sensing technology is very fast, and a series of breakthroughs have been made in terms of geotechnical sensing theories and technologies. A much wider range of applications has been observed at the same time. Many monitoring problems that are difficult to be solved by conventional methods have been solved. The widely used point-type geotechnical instrumentation technology is being replaced by the distributed sensing systems. Simultaneously, the electric sensors are being replaced by the fiber optic sensors. These 
achievements are reflected in the following aspects.

At the theoretical level, the criterion to evaluate the performance of sensing optical cables has been established, together with that of the deformation compatibility of the cable-soil interface. The calculation methods of critical confining pressure and critical depth of soil layer are proposed. The ultimate capacity of micro-anchors on the optical cable is proposed. In addition, several parameters have been introduced to describe the cable-soil bonding behavior. The characterization models of temperature characteristic value and soil moisture, water content, and seepage are established, which enables the distributed optical fiber in-situ monitoring of water field of rock and soil.

At the technological level, the secondary dismantling and synthetic cable is proposed. By modifying the fiber packaging material and optimizing the fiber structure, a series of robust sensitive-preserving sensing cables are developed. The encapsulation principles of fixed-point homogenization and the equivalent conversion are proposed and the sensing fiber with a different measuring range is developed. The carbon fiber reinforced polymer (CFRP) sensitized optical cable with internal heating function and the functional optical cable with smart and sensitive coating layer are invented, which provide powerful sensing elements for humidity and moisture content monitoring of rock and soil mass.

At the level of the monitoring system, the multi-parameter optical fiber monitoring system for the whole section of the borehole is established to improve the monitoring efficiency and reduce the overall cost. The optical fiber in-situ monitoring system of the soil moisture field is developed to realize the in-situ monitoring of large-area soil water field. The distributed fiber optic testing and monitoring systems for foundation piles and tunnels have been developed, which solve the problem of accurate and long-distance monitoring in geotechnical engineering.
However, despite the rapid development of the distributed fiber optic sensing technology in the past decade, it is still far from meeting the monitoring requirements of geo-engineering and needs further improvement in the data acquisition instrument for DFOS, the development of high temperature and anti-aging sensing optical fiber cable, and the installation technologies of sensing optical fiber cable. In recent years, there have been some new distributed fiber optic sensing technologies, such as the distributed fiber optic acoustic sensor technology (distributed acoustic sensing, DAS) and the weak grating array sensing technology. These technologies provide a new technical method and developing direction of geological engineering monitoring. In 2019, the world's top journals Science and Nature reported that based on the DAS technology, the undersea "dark fiber" was used to monitor earthquake, fault activity, ocean-solid earth interaction, and other research fields [89, 90]. Therefore, there is every reason to believe that with the development of the DFOS technology, geoengineering optical fiber monitoring will usher in another golden decade.

\section{Acknowledgment}

This work was supported by the National Natural Science Foundation of China (Grant Nos. 42030701, 41427801, and 42077233).

Open Access This article is distributed under the terms of the Creative Commons Attribution 4.0 International License (http://creativecommons.org/licenses/by/4.0/), which permits unrestricted use, distribution, and reproduction in any medium, provided you give appropriate credit to the original author(s) and the source, provide a link to the Creative Commons license, and indicate if changes were made.

\section{References}

[1] L. Schenato, "A review of distributed fibre optic sensors for geo-hydrological applications," Applied Sciences, 2017, 7(9): 896.

[2] M. Iten and A. M. Puzrin, "BOTDA road-embedded 
strain sensing system for landslide boundary localization," in Smart Sensor Phenomena, Technology, Networks, and Systems 2009. International Society for Optics and Photonics, San Diego, California, USA, 2009, pp. 729312-729316.

[3] W. R. Habel, D. Hofmann, H. Döring, H. Jentsch, A. Senze, and G. Kowalle, "Detection of a slipping soil area in an open coal pit by embedded fibre-optic sensing rods," in the 5th International Forum on Opto-electronic Sensor-Based Monitoring, China, 2014, pp. 1-7.

[4] A. Klar, P. J. Bennett, K. Soga, R. J. Mair, P. Tester, R. Fernie, et al., "Distributed strain measurement for pile foundation," Proceedings of the Institution of Civil Engineers - Geotechnical Engineering, 2006, 159(3): 135-144.

[5] L. L. K. Cheung, K. Soga, P. J. Bennett, Y. Kobayashi, B. Amatya, and P. Wright, "Optical fibre strain measurement for tunnel lining monitoring," Proceedings of the Institution of Civil Engineers Geotechnical Engineering, 2010, 163(3): 119-130.

[6] H. Mohamad, P. J. Bennett, K. Soga, R. J. Mair, and K. Bowers, "Behaviour of an old masonry tunnel due to tunnelling-induced ground settlement," Géotechnique, 2010, 60(12): 927-938.

[7] H. Mohamad, K. Soga, A. Pellew, and P. J. Bennett, "Performance monitoring of a secant-piled wall using distributed fiber optic strain sensing," Journal of Geotechnical and Geoenvironmental Engineering, 2011, 137(12): 1236-1243.

[8] H. Mohamad, K. Soga, P. J. Bennett, R. J. Mair, and C. S. Lim, "Monitoring twin tunnel interaction using distributed optical fiber strain measurements," Journal of Geotechnical and Geoenvironmental Engineering, 2012, 138(8): 957-967.

[9] H. Mohamad, K. Soga, and B. Amatya, "Thermal strain sensing of concrete piles using Brillouin optical time domain reflectometry," Geotechnical Testing Journal, 2014, 37(2): 333-346.

[10] L. Olivares, E. Damiano, R. Greco, L. Zeni, L. Picarelli, A. Minardo, et al., "An instrumented flume to investigate the mechanics of rainfall-induced landslides in unsaturated granular soils," Geotechnical Testing Journal, 2009, 32(2): 788-796.

[11] L. Picarelli, E. Damiano, R. Greco, A. Minardo, L. Olivares, and L. Zeni, "Performance of slope behavior indicators in unsaturated pyroclastic soils," Journal of Mountain Science, 2015, 12(6): 1434-1447.

[12] E. Damiano, B. Avolio, A. Minardo, L. Olivares, L. Picarelli, and L. Zeni, "A laboratory study on the use of optical fibers for early detection of pre-failure slope movements in shallow granular soil deposits," Geotechnical Testing Journal, 2017, 40(4): 529-541.

[13] Y. T. Ho, A. B. Huang, and J. T. Lee, “Development of a fibre Bragg grating sensored ground movement monitoring system," Measurement Science and Technology, 2006, 17(7): 1733-1740.

[14] Y. T. Ho, A. B. Huang, and J. Lee, "Development of a chirped/differential optical fiber Bragg grating pressure sensor," Measurement Science and Technology, 2008, 19(4): 045304.

[15] A. B. Huang, C. Wang, J. Lee, and Y. T. Ho, "Applications of FBG-based sensors to ground stability monitoring," Journal of Rock Mechanics and Geotechnical Engineering, 2016, 8(4): 513-520.

[16] J. H. Yin, "From constitutive modeling to development of laboratory testing and optical fiber sensor monitoring technologies," Chinese Journal of Geotechnical Engineering, 2011, 33(1): 1-15.

[17] H. F. Pei, P. Cui, J. H. Yin, H. Zhu, X. Chen, L. Pei, et al., "Monitoring and warning of landslides and debris flows using an optical fiber sensor technology," Journal of Mountain Science, 2011, 8(5): 728-738.

[18] H. F. Pei, J. H. Yin, H. Zhu, C. Y. Hong, W. Jin, and D. S. Xu, "Monitoring of lateral displacements of a slope using a series of special fibre Bragg grating-based in-place inclinometers," Measurement Science and Technology, 2012, 23(2): 025007.

[19] D. S. Xu and J. H. Yin, "Analysis of excavation induced stress distributions of GFRP anchors in a soil slope using distributed fiber optic sensors," Engineering Geology, 2016, 213: 55-63.

[20] B. Shi, D. Zhang, and H. H. Zhu, Distributed fiber optic sensing for geoengineering monitoring. Beijing: Science Press, 2019.

[21] J. F. Yan, B. Shi, H. H. Zhu, B. J. Wang, G. Q. Wei, and D. F. Cao, "A quantitative monitoring technology for seepage in slopes using DTS," Engineering Geology, 2015, 186: 100-104.

[22] D. F. Cao, B. Shi, H. H. Zhu, G. Q. Wei, S. E. Chen, and J. F. Yan, "A distributed measurement method for in-situ soil moisture content by using carbon-fiber heated cable," Journal of Rock Mechanics and Geotechnical Engineering, 2015, 7(6): 700-707.

[23] D. F. Cao, B. Shi, G. Q. Wei, S. E. Chen, and H. H. Zhu, "An improved distributed sensing method for monitoring soil moisture profile using heated carbon fibers," Measurement: Journal of the International Measurement Confederation, 2018, 123: 175-184.

[24] Y. L. Liu, H. Y. Sun, Y. Yu, W. Zhan, and Y. Q. Shang, "BOTDR monitoring analysis of anti-sliding pile internal force," Journal of Zhejiang University (Engineering Science), 2012, 46(2): 243-249.

[25] J. Chai, X. Huo, Y. Qian, D. Zhang, Q. Yuan, and Y. Li, "Model test for evaluating deformation and weighting of overlying strata by distributed optical fiber sensing," Journal of China Coal Society, 2018, 43(S1): 36-43.

[26] Y. Ding, B. Shi, X. Y. Bao, and J. Q. Gao, "Jacket 
effect on strain measurement accuracy for distributed strain sensors based on Brillouin scattering," Optica Applicata, 2006, 36(1): 57-67.

[27] F. Ansari and L. B. Yuan, "Mechanics of bond and interface shear transfer in optical fiber sensors," Journal of Engineering Mechanics, 1998, 124(4): 385-394.

[28] D. S. Li, H. N. Li, L. Ren, and G. B. Song, "Strain transferring analysis of fiber Bragg grating sensors," Optical Engineering, 2006, 45(2): 024402.

[29] Y. Zhang, P. Gao, H. M. Wang, B. Shi, and L. Qi, "Study on strain transfer characteristics of distributed optical fiber sensor under complex deformation condition," Journal of Disaster Prevention and Mitigation Engineering, 2013, 33: 566-572.

[30] M. Iten, A. M. Puzrin, D. Hauswirth, S. Foaleng-Mafang, J. C. Beugnot, and L. Thévenaz, "Study of a progressive failure in soil using BEDS," in the 20th International Conference on Optical Fibre Sensors, United Kingdom, October 5-9, 2009, pp. 75037S.

[31] D. Hauswirth, M. Iten, and A. M. Puzrin, "Detection of ground movements using soil-embedded distributed fiber optic sensors," in the 4th International Conference on Site Characterization ISC-4, Boca Raton, 2012, pp. 579-586.

[32] C. C. Zhang, H. H. Zhu, B. Shi, and J. K. She, "Interfacial characterization of soil-embedded optical fiber for ground deformation measurement," Smart Materials and Structures, 2014, 23(9): 095022.

[33] C. C. Zhang, H. H. Zhu, and B. Shi, "Role of the interface between distributed fibre optic strain sensor and soil in ground deformation measurement," Scientific Reports, 2016, 6(1): 1-9.

[34] B. Li, D. Zhang, X. Chen, J. Wang, and B. Shi, "Testing method on performance of deformation coupling between distributed sensing fiber and soil," Geological Journal of China Universities, 2017, 23(4): 633-639.

[35] L. Schenato, L. Palmieri, M. Camporese, S. Bersan, S. Cola, A. Pasuto, et al., "Distributed optical fibre sensing for early detection of shallow landslides triggering," Scientific Reports, 2017, 7(1): 1-7.

[36] K. E. Winters, M. C. Quinn, and O. D. S. Taylor, "Assessing the frictional resistance between fiber-optic sensor cable and different soil types," in Geo-Congress 2020: Modeling, Geomaterials, and Site Characterization, Minneapolis, 2020, pp. 164-171.

[37] ASTM, "Standard practice for use of distributed optical fiber sensing systems for monitoring the impact of ground movements during tunnel and utility construction on existing underground utilities," West Conshohocken, PA: ASTM, USA, 2014.
[38] C. C. Zhang, B. Shi, H. H. Zhu, B. J. Wang, and G. Q. Wei, "Toward distributed fiber-optic sensing of subsurface deformation: a theoretical quantification of ground-borehole-cable interaction," Journal of Geophysical Research: Solid Earth, 2020, 125(3): e2019JB018878.

[39] D. Hauswirth, M. Iten, R. Richli, and A. M. Puzrin, "Fibre optic cable and micro-anchor pullout tests in sand," in Physical Modelling in Geotechnics, Two Volume Set: Proceedings of the 7th International Conference on Physical Modelling in Geotechnics (ICPMG 2010), Zurich, Switzerland; Boca Raton, Florida, United States, June 28th-July 1st, 2010, pp. 337-342.

[40] D. Hauswirth, A. M. Puzrin, A. Carrera, and M. S. P. Wan, "Use of fibre-optic sensors for simple assessment of ground surface displacements during tunnelling," Geotechnique, 2014, 64(10): 837-842.

[41] H. H. Zhu, B. Shi, J. Zhang, J. F. Yan, and C. C. Zhang, "Distributed fiber optic monitoring and stability analysis of a model slope under surcharge loading," Journal of Mountain Science, 2014, 11(4): 979-989.

[42] R. You, L. Ren, and G. Song, “A novel fiber Bragg grating (FBG) soil strain sensor," Measurement, 2019, 139: 85-91.

[43] C. C. Zhang, H. H. Zhu, D. D. Chen, X. Y. Xu, B. Shi, and X. P. Chen, "Feasibility study of anchored fiber-optic strain-sensing arrays for monitoring soil deformation beneath model foundation," Geotechnical Testing Journal, 2018, 42(4): 966-984.

[44] C. C. Zhang, H. H. Zhu, S. P. Liu, B. Shi, and G. Cheng, "Quantifying progressive failure of micro-anchored fiber optic cable-sand interface via high-resolution distributed strain sensing," Canadian Geotechnical Journal, 2020, 57(6): 871-881.

[45] S. Zhang, "Study on mechanical coupling between anchored strain sensing optical cable and soil deformation," MEng dissertation, Nanjing University, Nanjing, China, 2019.

[46] C. C. Zhang, B. Shi, K. Gu, S. P. Liu, J. H. Wu, S. Zhang, et al., "Vertically distributed sensing of deformation using fiber optic sensing," Geophysical Research Letters, 2018, 45(21): 11732-11741.

[47] D. F. Cao, B. Shi, H. H. Zhu, H. I. Inyang, G. Q. Wei, and C. Z. Duan, "A soil moisture estimation method using actively heated fiber Bragg grating sensors," Engineering Geology, 2018, 242: 142-149.

[48] V. R. Tarnawski and W. H. Leong, "Thermal conductivity of soils at very low moisture content and moderate temperatures," Transport in Porous Media, 2000, 41(2): 137-147.

[49] M. Y. Sun, B. Shi, D. Zhang, J. Liu, J. Y. Guo, G. Q. Wei, et al., "Study on calibration model of soil water content based on actively heated fiber-optic FBG method in the in-situ test," Measurement, 2020, 165: 
108176.

[50] J. Liu, M. Y. Sun, B. Shi, G. Q. Wei, J. Y. Guo, and $\mathrm{X}$. Zheng, "Feasibility study on the actively heated FBG methods for dry density measurement," Chinese Journal of Geotechnical Engineering, 2020, 43(2): 390-396.

[51] J. Y. Guo, B. Shi, M. Y. Sun, C. C. Zhang, G. Q. Wei, and J. Liu, "Characterization of an ORMOCER $\AA$-coated FBG sensor for relative humidity sensing," Measurement, 2021, 171(4): 108851.

[52] D. M. Liu, T. He, Z. J. Xu, and Q. Z. Sun, "New type of microstructure-fiber distributed acoustic sensing technology and its applications," Journal of Applied Sciences - Electronics and Information Engineering, 2020, 38(2): 296-309.

[53] D. Zhang, J. C. Wang, B. Li, and B. Shi, "Fatigue characteristics of distributed sensing cables under low cycle elongation," Smart Structures and Systems, 2016, 18(6): 1203-1215.

[54] G. Q. Wei, "Distributed monitoring for engineering soil deformation with optical fiber sensors," Ph.D dissertation, Nanjing University, Nanjing, China, 2008.

[55] Y. J. Sun, "Bank slope multi-fields monitoring based on fiber optic sensing technologies and stability evaluation study," Ph.D dissertation, Nanjing University, Nanjing, China, 2015.

[56] B. Shi, H. Z. Xu, D. Zhang, D. Yong, H. L. Cui, B. Chen, et al., "Feasibility study on application of BOTDR to health monitoring for large infrastructure engineering," Chinese Journal of Rock Mechanics and Engineering, 2004, 23(3): 493-499.

[57] Y. Lu, B. Shi, G. Q. Wei, S. E. Chen, and D. Zhang, "Application of a distributed optical fiber sensing technique in monitoring the stress of precast piles," Smart Materials \& Structures, 2012, 21(11): 115011.

[58] L. Pelecanos and K. Soga, "Development of load-transfer curves for axially-loaded piles using fiber-optic strain data, finite element analysis and optimization," in the 9th European Conference on Numerical Methods in Geotechnical Engineering, Portugal, 2018, pp. 1025-1030.

[59] Y. J. Sun, X. Li, R. Cun, H. Z. Xu, and A. M. Han, "Distributed fiber optic sensing and data processing of axial loaded precast piles," IEEE Access, 2020, 8: 169136-169145.

[60] B. Shi, H. Xu, B. Chen, D. Zhang, Y. Ding, H. Cui, et al., "A feasibility study on the application of fiber-optic distributed sensors for strain measurement in the Taiwan Strait Tunnel project," Marine Georesources and Geotechnology, 2003, 21(3-4): 333-343.

[61] A. Klar, I. Dromy, and R. Linker, "Monitoring tunneling induced ground displacements using distributed fiber-optic sensing," Tunnelling and
Underground Space Technology, 2014, 40: 141-150.

[62] X. Wang, B. Shi, G. Q. Wei, S. E. Chen, H. Zhu, and T. Wang, "Monitoring the behavior of segment joints in a shield tunnel using distributed fiber optic sensors," Structural Control and Health Monitoring, 2018, 25(1): e2056.

[63] M. Fajkus, J. Nedoma, P. Mec, E. Hrubesova, R. Martinek, and V. Vasinek, "Analysis of the highway tunnels monitoring using an optical fiber implemented into primary lining," Journal of Electrical Engineering, 2017, 68(5): 364-370.

[64] H. G. Yu, X. B. Bing, H. U. Tao, S. Y. Yin, and Y. C. Han, "Fiber sheath effect in tunneling monitoring based on BOTDR technology," Rock and Soil Mechanics, 2017, 38(8): 2441-2447.

[65] G. Yao, "Loess tunnel lining cracking analysis and monitoring system research," in the 1st International Conference on Transportation Infrastructure and Materials (ICTIM 2016), China, 2016: 760-766.

[66] S. Manandhar, K. Miyazoe, S. Fukuoka, T. Hino, Dennes T. Bergado, and T. Koumoto, "Observation of static load of 1-shaped retaining wall constructed on short wooden pile using fiber optic geogrid BOTDR method," Indian Geotechnical Journal, 2016, 46(4): 398-407.

[67] C. Y. Hong, Y. F. Zhang, G. W. Li, M. X. Zhang, and Z. X. Liu, "Recent progress of using Brillouin distributed fiber optic sensors for geotechnical health monitoring," Sensors and Actuators A: Physical, 2017, 258: 131-145.

[68] C. Zhu, K. Zhang, H. Cai, Z. Tao, B. An, M. He, et al., "Combined application of optical fibers and CRLD bolts to monitor deformation of a pit-in-pit foundation," Advances in Civil Engineering, 2015, 2019(1): 1-16.

[69] D. Zhang, Q. Xu, A. Bezuijen, G. Zheng, and H. X. Wang, "Internal deformation monitoring for centrifuge slope model with embedded FBG arrays," Landslides, 2017, 14(1): 407-417.

[70] M. Zeng, H. Zhao, D. Wu, H. Chen, and J. Cai, “A vibration-based traffic monitoring system using distributed optical sensing technology," Journal of Testing and Evaluation, 2020, 48(3): 1799-1813.

[71] M. Bonopera, K. C. Chang, C. C. Chen, Z. K. Lee, Y. C. Sung, and N. Tullini, "Fiber Bragg grating-differential settlement measurement system for bridge displacement monitoring: case study," Journal of Bridge Engineering, 2019, 24(10): 05019011.

[72] C. Du, S. Dutta, P. Kurup, T. Yu, and X. Wang, “A review of railway infrastructure monitoring using fiber optic sensors," Sensors and Actuators A: Physical, 2020, 303: 111728.

[73] H. H. Zhu, B. Shi, and C. C. Zhang, "FBG-based monitoring of geohazards: current status and trends," Sensors, 2017, 17(3): 452.

[74] Y. J. Sun, D. Zhang, B. Shi, H. J. Tong, G. Q. Wei, 
and X. Wang, "Distributed acquisition, characterization and process analysis of multi-field information in slopes," Engineering Geology, 2014, 182: 49-62.

[75] Y. Sun, B. Shi, D. Zhang, H. Tong, G. Wei, and $\mathrm{H}$. Xu, "Internal deformation monitoring of slope based on BOTDR," Journal of Sensors, 2016, 2016: $1-8$.

[76] K. Gu, B. Shi, C. Liu, H. Jiang, T. Li, and J. Wu, "Investigation of land subsidence with the combination of distributed fiber optic sensing techniques and microstructure analysis of soils," Engineering Geology, 2018, 240: 34-47.

[77] H. Han, B. Shi, and L. Zhang, "Prediction of landslide sharp increase displacement by SVM with considering hysteresis of groundwater change," Engineering Geology, 2021, 280: 105876.

[78] S. P. Liu, B. Shi, K. Gu, C. Zhang, and P. Yang, "Land subsidence monitoring in sinking coastal areas using distributed fiber optic sensing: a case study," Natural Hazards, 2020, 103(3): 3043-3061.

[79] H. Sang, D. Zhang, Y. Gao, L. Zhang, G. Wang, B. Shi, et al., "Strain distribution based geometric models for characterizing the deformation of a sliding zone," Engineering Geology, 2019, 263: 105300 .

[80] D. Zhang, J. C. Wang, P. S. Zhang, and B. Shi, "Internal strain monitoring for coal mining similarity model based on distributed fiber optical sensing," Measurement, 2017, 97: 234-241.

[81] L. Zhang, B. Shi, H. Zhu, X. B. Yu, H. Han, and X. Fan, "PSO-SVM-based deep displacement prediction of Majiagou landslide considering the deformation hysteresis effect," Landslides, 2021, 18(1): 179-193.

[82] M. Gil-Rodríguez, L. Rodríguez-Sinobas, J. Benítez-Buelga, and R. Sánchez-Calvo, "Application of active heat pulse method with fiber optic temperature sensing for estimation of wetting bulbs and water distribution in drip emitters," Agricultural Water Management, 2013, 120: 72-78.

[83] C. Sayde, C. Gregory, M. Gil-Rodriguez, N. Tufillaro, and J. S. Selker, "Feasibility of soil moisture monitoring with heated fiberoptics," Water Resources Research, 2010, 46(6): W06201.

[84] J. H. Wu, B. Shi, D. F. Cao, H. T. Jiang, X. F. Wang, and $\mathrm{K} . \mathrm{Gu}$, "Model test of soil deformation response to draining-recharging conditions based on DFOS," Engineering Geology, 2017, 226: 107-121.

[85] R. Wu, V. Martin, J. McKenzie, S. Broda, B. Bussière, M. Aubertin, et al., "Laboratory-scale assessment of a capillary barrier using fibre optic distributed temperature sensing (FO-DTS)," Canadian Geotechnical Journal, 2020, 57(1): 115-126.

[86] J. Benítez-Buelga, L. Rodríguez-Sinobas, R. S. Calvo, M. Gil-Rodríguez, C. Sayde, and J. S. Selker, "Calibration of soil moisture sensing with subsurface heated fiber optics using numerical simulation," Water Resources Research, 2016, 52(4): 2985-2995.

[87] C. Sayde, J. B. Buelga, L. Rodriguez-Sinobas, L. El Khoury, M. English, N. van de Giesen, et al., "Mapping variability of soil water content and flux across 1-1000 m scales using the actively heated fiber optic method," Water Resources Research, 2014, 50(9): 7302-7317.

[88] A. M. Striegl and S. P. Loheide II, "Heated distributed temperature sensing for field scale soil moisture monitoring," Groundwater, 2012, 50(3): 340-347.

[89] N. J. Lindsey, T. C. Dawe, and J. B. Ajo-Franklin, "Illuminating seafloor faults and ocean dynamics with dark fiber distributed acoustic sensing," Science, 2019, 366(6469): 1103-1107.

[90] E. F. Williams, M. R. Fernández-Ruiz, R. Magalhaes, R. Vanthillo, and H. F. Martins, "Distributed sensing of microseisms and teleseisms with submarine dark fibers," Nature Communications, 2019, 10(1): 1-11. 